\title{
Co-Operation and Self-Organization
}

\author{
Christian Fuchs
}

Institute for Design and Technology Assessment, Vienna University of Technology

Favoritenstr.9-11, 1040 Vienna, Austria; christian@igw.tuwien.ac.at

\begin{abstract}
Co-operation has its specific meanings in physical (dissipative), biological (autopoietic) and social (re-creative) systems. On upper hierarchical systemic levels there are additional, emergent properties of co-operation, co-operation evolves dialectically. The focus of this paper is human cooperation. Social systems permanently reproduce themselves in a loop that mutually connects social structures and actors. Social structures enable and constrain actions, they are medium and outcome of social actions. This reflexive process is termed re-creation and describes the process of social selforganization. Co-operation in a very weak sense means coaction and takes place permanently in re-creative systems: two or more actors act together in a co-ordinated manner so that a new emergent property emerges. Co-action involves the formation of forces, environment and sense (dispositions, decisions, definitions). Mechanistic approaches conceive coaction in terms of rational planning, consciousness, intention, predictability, and necessity. Holistic approaches conceive coaction in terms of spontaneity, unconscious and unintended actions, non-predictability, chance. Dialectic approaches conceive co-action in terms of a unity of rational planning and spontaneous emergence, a unity of conscious and unconscious aspects and consequences, and a unity of necessity and chance. Co-operation in a strong sense that is employed in this paper means that actors work together, create a new emergent reality, have shared goals, all benefit from co-operating, can reach their goals in joint effort more quickly and more efficiently than on an individual basis, make concerted use of existing structures in order to produce new structures, learn from each other mutually, are interconnected in a social network, and are mutually dependent and responsible. There is a lack of cooperation, self-determination, inclusion and direct democracy in modern society due to its antagonistic structures. This today culminates in global problems such as the ecological crisis, high risk technologies, poverty, unemployment, wars, armed
\end{abstract}

conflicts, terrorism, etc. In order to solve these problems our social systems need re-design in terms of ecological sustainability, alliance technology, participatory economy, participatory democracy, and participatory culture. Participation is an integrated notion that is based on co-operation, selfdetermination, and inclusion in multiple dimensions. A system can be considered as participatory if power in the system is distributed in such a way that all members and concerned individuals can own the system co-operatively and can produce, decide and live in the system co-operatively. Participation is frequently understood in the very narrow sense of concerned people taking somehow part in decision processes. Such an understanding is limited to the political dimension and says nothing about the scope and dimension of participation. There are several dimensions of participation in a social system or in society: producing, owning, consuming (economic dimension), deciding, goal-setting, evaluating (political dimension), forming knowledge/norms/values/ images/visions, communicating, networking, self-realizing (cultural dimension). Participation in each of these ten dimensions can be low, medium or high/full. The participation matrix describes the degree of participation in an organization/society with the help of the three dimensions of economy, politics and culture and an analysis of the scope of participation (economic, political, cultural).

Keywords: co-operation, social self-organization, social information, society, re-creativity

Acknowledgement: This paper is based on research done within the framework of the project 'Human Strategies in Complexity: Philosophical Foundations for a Theory of Evolutionary Systems' (http://www.self-organization.org) funded by INTAS (\#0298) and supported by the Austrian Federal Ministry of Education, Science and Culture.

\section{Introduction ${ }^{1}$}

In recent times the terms co-operation and participation have been frequently used in scientific research and publications. Concepts employed and developed in recent scientific articles include: co-operative governance, co-operative managerial capitalism, co-operative research, co-operative software agents, co-

\footnotetext{
1 An earlier version of this article has been published as: Fuchs, Christian (2003) Co-operation in Complex, Self-Organising, Information-Generating Systems. In: Wilby, Jennifer/Allen, Janet K. (Eds.) (2003) Proceedings of the $47^{\text {th }}$ Annual Conference of the International Society for the Systems Sciences (ISSS): Agoras of the Global Village, Iraklion, Crete, July $7^{\text {th }}-11^{\text {th }}, 2003$. ISBN 09740735-1-2. This version is a completely reworked and extended one.
} 
ooperative action, civilian-military co-operation, co-operative species, co-operative learning, distributed team co-operation, co-operative security, computer supported co-operative work, co-operative enterprises, co-operative destination marketing, co-operative information systems, co-operative co-evolution, cooperative scheduling, co-operative ecosystem management, co-operative design, interorganizational cooperation, strategic co-operation, co-operative ventures, new generation co-operatives (NGCs), cooperative inquiry, co-operative marketing associations, inter-institutional co-operation, metabolic cooperation, co-operative teaching teams, co-operative collectives, co-operative interaction, tacit cooperation, innovative network co-operation, co-operative advertising, co-operative intervention, telematic co-operation, co-operative firms, etc.

There seems to be an increased interest in co-operation, however a general concept of co-operation is missing. The aim of this paper is to outline some general and specific aspects of co-operation. Cooperation is considered in a broad sense as a phenomenon that can be found in all complex, selforganizing system. A general theory of information and self-organization seems to be a suitable framework for developing a general concept of co-operation because it is interdisciplinary in method and focuses on synergetical interactions that have emergent results. Considering evolution as a self-organized process where new levels of organisation with emergent qualities emerge in phases of instability, a hierarchy of system types can be constructed (see Ahl/Allen 1996, Laszlo 1996, Salthe 1985, 1993). The hierarchy starts from physical and chemical (dissipative) systems, goes up to living (autopoietic) systems and finally to social (re-creative) systems (Fenzl/Hofkirchner 1997, Fleissner/Hofkirchner 1996, Fuchs/Hofkirchner 2002c; Hofkirchner 1998a, b, 1999a, b, 2001, 2002b). Higher levels incorporate lower ones, have higher complexity and emergent properties. Phenomena of co-operation can be found on each of these levels. There are on the one hand general aspects of co-operation that apply to all levels, on the other hand one can at each level find specific aspects. Co-operation is itself an evolving phenomenon, during the course of its evolution new higher emergent qualities and levels of co-operation arise that can't be reduced to lower levels or qualities. Co-operation is shaped by a dialectic of generality and concreteness.

I will first point out general aspects of information, self-organization and co-operation (section 2) that apply to all complex systems. Advancing from lower to higher steps of evolution, I will then point out aspects of physical and biological co-operation (section 3) and social co-operation (sections 4-9). Societal co-operation is the main focus of this paper. In order to develop foundations for a general concept of social co-operation, it seems necessary to outline some general foundations of a theory of social selforganization. I will summarise some of the work I have done in this area of research in section 4 that deals with information and self-organization in society. Section 5 deals with co-action and co-operation in society, co-operation will be interpreted in a broad and a more narrow sense. The latter brings up the topic of selfdetermination, hence the focus of part 6 will be the relationship of self-organization and self-determination. Some scientists oppose the advancement of general concepts of social co-operation because they assume that competition forms the essence of society. I will discuss the approach of Friedrich August Hayek who is one of the most important representatives of such theories in section 7 in order to show why I think that co-operation is superior to competition. In section 8 I will show that in various areas of research such as ecology, engineering, economics, political theory, and cultural studies there is a shift of focus from competition and heteronomy to co-operation and self-determination that puts forward the idea of an overall societal shift towards a co-operative society. I will conclude (section 9) that co-operation is a principle of social systems design that can increase the possibility that humankind can solve the global problems.

The main hypothesis that I put forward is that the social forces have an increasingly co-operative character, whereas the social relationships are still dominated by fierce competition, heteronomy and asymmetrical distributions of power. Social forces are not only economic productive forces, but technological, natural, economic, political and cultural structures that enable and constrain human and societal development. The antagonistic imbalance and asynchronicity of social forces and social relationships results in tensions and increasing global societal problems. Co-operation seems to be a principle of shaping social relationships that can further a sustainable development of society. 


\section{General Aspects of Information, Self-Organisation and Co-operation}

Emergence and self-organization are two particularly important concepts of the sciences of complexity. that this book and the research project "Human Strategies in Complexity" focus on. We want to give a general characterisation of both concepts.

Aspects of emergence are:

- Synergism: Emergence is due to the productive interaction between entities. Synergy is a very general concept that refers "to combined or 'co-operative' effects - literally, the effects produced by things that 'operate together' (parts, elements or individuals)" (Corning 1998: 136). Synergy takes place and shapes systems on all organisational levels of matter, it is a fundamental quality of matter. Synergies between interacting entities are the cause of the evolution and persistence of emergent systems.

- Novelty: On a systemic level different from the level of the synergetically interacting entities new qualities show up. Emergent qualities are qualities that have not been previously observed and have not previously existed in a complex system ("a whole is more than the sum of its parts").

- Irreducebility: The new produced qualities are not reduceable to or derivable from the level of the producing, interacting entities.

- Unpredictability: The form of the emergent result and the point of emergence can't be fully predicted.

- Coherence/Correlation: Complex systems with emergent qualities have some coherent behaviour for a certain period of time (Goldstein 1999). This coherence spans and correlates the level of the producing entities into a unity on the level of emergence (ibid.).

- Historicity: Emergent qualities are not pre-given, but the result of the dynamical development of complex systems.

Emergence is a fundamental quality of self-organising systems. Aspects of self-organisation are:

- Systemness: Self-organisation takes place in a system, i.e. in coherent whole that has parts, interactions, structural relationships, behaviour, state, and a border that delimits it from its environment.

- Complexity: Self-organising systems are complex systems. The term "complexity" has three levels of meaning: 1. there is self-organization and emergence in complex systems (Edmonds 1999), 2. complex systems are not organised centrally, but in a distributed manner; there are many connections between the system's parts (Kauffman 1993, Edmonds 1999), 3. it is difficult to model complex systems and to predict their behaviour even if one knows to a large extent the parts of such systems and the connections between the parts (Heylighen 1996, 1997; Edmonds 1999). The complexity of a system depends on the number of its elements and connections between the elements (the system's structure). According to this assumption, Kauffman (1993) defines complexity as the "number of conflicting constraints" in a system, Heylighen (1996) says that complexity can be characterised by a lack of symmetry (symmetry breaking) which means that "no part or aspect of a complex entity can provide sufficient information to actually or statistically predict the properties of the others parts" and Edmonds (1996) defines complexity as "that property of a language expression which makes it difficult to formulate its overall behaviour, even when given almost complete information about its atomic components and their inter-relations". Aspects of complexity are things, people, number of elements, number of relations, non-linearity, broken symmetry, non-holonic constraints, hierarchy and emergence (Flood/Carson 1993).

- Cohesion: Cohesion means the closure of the causal relations among the dynamical parts of a dynamical particular that determine its resistance to external and internal fluctuations that might disrupt its integrity (Collier 2003, 2004). It is a "dividing glue" of dynamic entities (ibid.). 
- Openness: self-organisation can only take place if the system imports energy which is transformed within the system, as a result energy is exported. Self-organisation is entropy reduction.

- Bottom-up-Emergence: A perturbation causes the system's parts to interact synergetically in such a way that at least one new quality on a higher level emerges.

- Downward Causation: Once new qualities of a system have emerged they along with the other structural macro-aspects of the system influence, i.e. enable and constrain, the behaviour of the system's parts. This process can be described as top-down-emergence if new qualities of certain parts (seen as wholes or systems themselves) show up.

- Non-linearity: Emergence is based on non-linear causality, i.e. causes and effects can't be mapped linearly: similar causes can have different effects and different causes similar effects; small changes of causes can have large effects whereas large changes can also only result in small effects (but nonetheless it can also be the case that small causes have small effects and large causes large effects).

- Feedback loops, Circular causality. there are feedback loops within a self-organising system; circular causality involves a number of processes $p_{1}, p_{2}, \ldots, p_{n}(n \geq 1)$ and $p_{1}$ results in $p_{2}, p_{2}$ in $p_{3}, \ldots, p_{n-1}$ in $p_{n}$ and $p_{n}$ in $p_{1}$. Self-organisation can be envisioned as a circular loop in the sense that the level of elements and the structural level are complexly mutually causally related. This mutual relationship is productive, complex, and non-linear.

- Information: All self-organising systems are information generating systems. Information is the processual relationship between self-organising material units that form a coherent whole that has emergent properties.

- Relative chance: there are both aspects of chance and necessity in self-organising systems; certain aspects are determined, whereas others are relatively open and according to chance

- Hierarchy: The self-organisation of complex systems produces a hierarchy in two distinctive senses: 1. The level of emergence is a hierarchically higher level, i.e. it has additional, new emergent qualities that can't be found on the lower level which is comprised by the components. The upper level is a sublation of the lower level. 2. Self-organisation results in an evolutionary hierarchy of different system types, these types are hierarchically ordered in the sense that upper levels are more complex and have additional emergent qualities.

- Globalisation and localisation: Bottom-up-emergence means the globalising sublation of local entities, downward causation the localisation of more global qualities.

- Unity in Plurality (Generality and Specifity): On the one hand each type of self-organising system is characterised by a number of distinctive qualities that distinguish it from other self-organising systems. On the other hand each type of self-organising system also shares general principles and qualities with all other types of self-organising systems. Both generality/unity and specifity/plurality are characteristic of self-organising systems.

Besides cognition and communication, co-operation is an aspect of information generation in complex, self-organizing systems. Co-operation is not solely a human activity, there are prior types of co-operation in physical and biological systems. The self-organization of matter is an evolutionary, dialectical process that results in an evolutionary hierarchy of system types (Fuchs 2002a). In phases of instability, levels are sublated and higher levels emerge. The old level is no longer the highest one (elimination), a higher level contains aspects of lower levels (preservation) and there are new, emergent qualities on higher levels (lifting up). Co-operation is a dialectically evolving phenomenon. Co-operability is the informational aspect of the systemic capabilities of a self-organizing system. The system capability of a physical (dissipative) system is synergism, of a living (autopoietic) system regenerability and of a social (re-creative) system productivity (Hofkirchner 2002a). The co-operative dimension of information generation is referring to synergy/cohesion/collectivity in physical systems, to association in living systems and to identity in social systems (ibid.). Collectivity means that in self-organizing physical systems there is a coherent behaviour of the system's components (self-alteration) (Hofkirchner 2002b). The regenerability of living systems 
consists of corresponding behaviour in reaction to signals (re-structuration) and co-ordination that is based on correspondence (self-maintenance) (ibid.).

Cognition, co-operation and communication are phenomena that can be found in different forms in all self-organizing systems (fig. 1). All self-organizing systems are information-generating systems. Information is a relationship that exists as a relationship between specific organisational units of matter. Reflection (Widerspiegelung) means reproduction of and reaction as inner system-changes to influences from the outside of a system. There is a causal relationship between the result of reflection and the reflected. The reflected causes structural changes, but doesn't mechanically determinate them. There is a certain, relative autonomy of the system, this autonomy can be described as a degree of freedom from perturbations. On the different organisational levels of matter we find different degrees of freedom. This degree increases along with complexity if we go up the hierarchy from physical-chemical to living and finally social systems. The causal relationship between the reflected and the result of reflection is based on a dialectic relationship of freedom and necessity. Information is an objective relationship between the reflected, the result of reflection inside the system's structure and the realisation of functions of the system within the reflected environment of the system (see Hörz/Röseberg 1981: 273ff). This means that information is a relationship of reflection between a system and its environment, to be more precise between units of organised matter. Information is not a structure given in advance, it is produced within material relationships. "Information is a physical structure and at the same time a structure which dominates the physical forces. [...] Information is not a physical substance, it is instead temporarily 'attached' to it. Information must be understood as a specific effect and as a relationship" (Fuchs-Kittowski 1997: 559f).

When two systems interact (see fig. 1), they enter an objective relationship, i.e. a (mutual) causal relationship is established. A portion of subjective, systemic information ("cognition") is communicated from system A to system B (and vice versa, "communication"). This causes structural changes in the other system. If there is an information relationship between the two systems, it is determined that there will be causal interactions and structural effects. The structure of the systems (structural, subjective information) changes, but we don't know to which extent this will actually be the case, which new subjective information will emerge, which information (structures) will be changed etc. There are degrees of autonomy and freedom (=chance). If structural changes in system $B$ take place and are initiated by system $A$, this means an objectification of subjective information of $A$ in $B$ from the point of view of $A$. From the point of view of $B$ it means subjectification of objective information from the environment. In a communication process, this also takes place the other way round. As a result of communication it cannot only be the case that an objectification of information in some of the involved systems takes place, it can also be the case that due to the synergies between the systems new qualities (information) emerge in their shared environment ("cooperation"). Structural, subjective information of the involved systems is co-ordinated, synergies arise and hence something new is produced commonly in a self-organization process. The new structure or system that arises is an objectification of subjective information of the involved systems. Information in selforganizing systems has cognitive (subjective), communicative (new subjective information (=structures) emerges in systems due to interaction) and co-operative aspects (interaction results in synergies that cause the emergence of new, objectified information in the shared environment of the involved systems).

These general aspects of co-operation can be found in all complex, self-organizing systems. However, there are qualities that distinguish co-operation in physical, biological and human systems because in the evolutionary development of matter there are different levels of complexity. Increased complexity means the emergence of new qualities of matter and hence also the emergence of new qualities of co-operation because co-operation is a fundamental aspect of matter. Advancing from less complex to more complex levels of evolution, I first want to discuss physical and biological co-operation. 


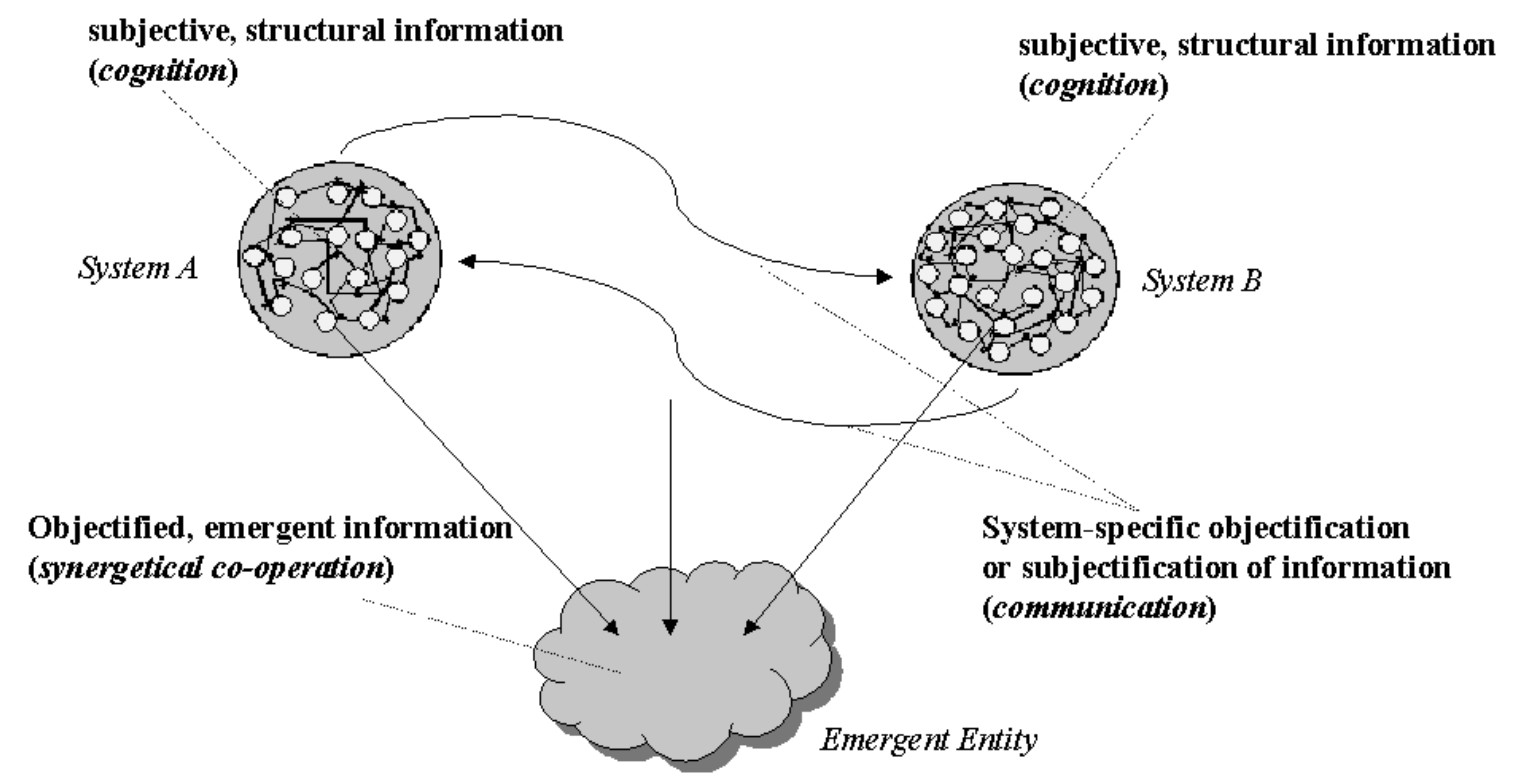

Figure 1: A general model of the three aspects of information-generation (cognition, communication and co-operation) in self-organizing systems

\section{Physical and Biological Co-operation}

Co-operation is a cohesive and synergetical force in self-organizing systems. Cohesion means the closure of the causal relations among the dynamical parts of a dynamical particular that determine its resistance to external and internal fluctuations that might disrupt its integrity (Collier 2003, 2004). It is a "dividing glue" of dynamic entities (ibid.). Co-operation as a cohesive force can produce synergies that result in new higher, emergent properties of a system. Synergy in a physical system means the unity of attraction and repulsion. The basic forms of all motion of matter are approximation and separation, contraction and expansion - attraction and repulsion which are dialectical poles of movement and the essence of matter (Engels 1886a: 356f, Hegel 1874: §§97f).

One example of physical co-operation in self-organizing systems are the Bénard-cells: A special liquid is heated at a certain temperature $\mathrm{t} 2$ from beneath and cooled down at a certain temperature $\mathrm{t} 1$ from above. So there is a temperature-difference $\Delta \mathrm{t}=\mathrm{t} 2-\mathrm{t} 1$ which develops and is the control parameter of the system. At $\Delta t=0$ the system is in equilibrium, if the temperature gradient rises, at a certain critical value a new pattern emerges in the liquid that looks like honeycombs. The liquid particles are located in layers, lower layers are due to the temperature warmer than upper ones, they expand and their density decreases. At the beginning of the critical phase, a first small fluctuation is caused which means that a particle is thrown out of its position in an initial layer and enters an upper or lower layer. In which layer this fluctuation will occur is not predetermined. Fluctuations only take place if a certain threshold of the control parameter $\Delta t$ is crossed. The fluctuation intensifies itself, more and more liquid particles are detached from their stationary position, disorder, chaos and collective motion shows up. The liquid particles arrange in cells that have different forms (round, square, broad, thin, large, small etc.). These forms are expressed as modes, which are elementary forms of motion. At a certain point of time, several types of cells exist. Finally one type can assert itself, and as a result there is one dominant form due to a selection process within the system. As a result of the superimposition of many of the same form, a pattern emerges that looks like a honeycomb. So from an initial chaos of particles, order has emerged. At a certain value of the temperature gradient, this order disappears. In this process, it is determined that order will emerge, that there will be initial fluctuations which spread out and that one of several types of roles will be selected. But it is not determined in which layer the fluctuation will be caused, how exactly the cell-types will look like and which one will be selected. This experiment will only be successful if energy in the form of a temperature difference is applied to the system. 
Another example that is frequently used in order to explain self-organization is the functioning of a laser (see Haken 1987). A laser consists of an active medium that is situated between two mirrors. This medium is either a gas that is radiating due to the discharge caused by current entry or a crystal that is pumped through a flash lamp. E.g. a ruby with chrome ions can be used. The atoms of the crystal are stimulated by the flashes, an electron changes its trajectory, it jumps from an inner trajectory to an outer one and takes up energy from the flash lamp. It spontaneously returns to its former trajectory and emits energy in the form of a light wave. So due to the stimulation of the atoms caused by the flash lamp, the atoms emit light waves. The two mirrors again and again reflect the light. First, there is chaos of light waves. A light wave can hit other atoms and force them to intensify its own light. By such processes, the light waves reach certain amplitudes. Hermann Haken says that one light wave "enslaves" other ones; this means that it becomes dominant and orders the system. As a result an ordered light wave, the laser beam, emerges. From chaos of light waves, an ordered pattern emerges. The decisive control parameter is current-supply; the system can only enter criticality if the current reaches a certain threshold. A light wave is caused by a fluctuation, i.e. an electron returns to its inner trajectory and emits energy; a light wave can intensify itself by "enslaving" electrons. Such intensification always means circular causality, because an entity causes the behaviour of another entity and this behaviour results in a transformation of the first entity. Due to such intensifications, the system enters a state of chaos/instability/bifurcation. A certain light wave is selected and determines the emergence of the laser beam. It is determined that a laser beam will emerge, that fluctuations and intensification will be caused; but it is not determined how this exactly takes place and which light wave will order the system.

These examples show that co-operation takes place as coherence/synergy in physical systems. The elements of the systems first enter a chaotic state, in which they repulse each other. Chaos, noise and instability mean a disordered movement of the elements of a complex system. But this repulsion is one that turns into attraction, because the elements interact, there are processes of ordering and selection, i.e. attraction takes place as the emergence of a coherent whole and new quality. Synergies between elements of a physical system are not due to some higher, eschatological force; they take place and result in emergent order due to the ability of matter to structure itself. Patterns as forms of coherent movement result from information generation in dissipative systems. The emergence of order (patterns) from noise in physical systems is due to the synergetic co-operation, i.e. productive interactions of the system's components.

Synergy is a very general concept that refers "to combined or 'co-operative' effects - literally, the effects produced by things that 'operate together' (parts, elements or individuals)" (Corning 1998: 136). Emergent properties exist in all complex, self-organizing systems. The question "How can the existence of selforganization be explained?" can be answered by saying: Self-organization is due to synergies between the components of a system that produce emergent phenomena. Synergy takes place and shapes systems on all organisational levels of matter. Synergy is a fundamental quality of matter. "The synergies that emergent systems produce are the very cause of their evolution, and persistence" (Corning 2001). This equals saying that matter is causa sui, it is producing and organising itself and is its own reason (Fuchs 2002a, 2003b). Hence there is may be no theoretical need to assume a first mover of the world that is not moved itself and to think of the emergence of the world in terms of a creatio-ex-nihilo. The substance of matter is that it is in permanent movement and permanently produces itself, i.e. it organises itself on various organisational levels (ibid.).

In all living systems, signals that result in corresponding behaviour and co-ordination form a foundation of co-operation. These two aspects enable such systems to maintain themselves. The works of Charles Darwin have been interpreted in such a way by Alfred R. Wallace, Thomas Huxley and others that today it seems quite common in our Western culture to assume that survival of the fittest and struggle for existence are the only principles of natural evolution. Pupils are in fact still taught that evolution means survival of the fittest. Overemphasizing such assumptions seems questionable if one takes a look at the rich variety of co-ordination in the natural world: the common work of ants, termites, bees; swarms of 
crustaceans, associations of male and female animals in order to take care of their offspring, associations for hunting and gathering (e.g. birds and mammals), flock of birds, birds of passage, the singing and dances of birds, scouting squads in flocks of cranes, common brooding by birds such as parrots, colonies of mice, rats, gophers, marmots; packs of wolfs, coyotes, jackals; the games of rabbits, cats, dogs; the social life of horses, reindeers, roes, antelopes, gazelles, ibexes; and the gregarious life of elephants and monkeys, etc.

Peter Kropotkin (1914; see also 1913: chapter 5,6) argues that a detailed study of nature shows that co-operation within animal species is a main aspect of evolution. Besides mutual struggle there would be another important principle that drives evolution: mutual aid. Mutual aid would be an instinct of animal and humans that promotes survival of the species. "As soon as we study animals - not in laboratories and museums only, but in the forest and the prairie, in the steppe and the mountains - we at once perceive that though there is an immense amount of warfare and extermination going on amidst various species, and especially amidst various classes of animals, there is, at the same time, as much, or perhaps even more, of mutual support, mutual aid, and mutual defence amidst animals belonging to the same species or, at least, to the same society. Sociability is as much a law of nature as mutual struggle." (Kropotkin 1914: 26).

Darwin stressed himself that the struggle for existence between individuals should be understood in a metaphorical sense and includes dependency, harmony and co-ordination. Darwin wrote that the term "struggle for existence" should be taken in its "large and metaphorical sense including dependence of one being on another, and including (which is more important) not only the life of the individual, but success in leaving progeny" (Darwin 1859). He also wrote about co-operation in the animal world that those "communities ... which included the greatest number of the most sympathetic members would flourish best, and rear the greatest number of offspring" (Darwin 1874). Darwin considered competition, killing and destruction only as one form of the struggle for existence in nature, but he never questioned the assumed utmost importance of this one principle. This also laid the grounds for the vulgarisation of his works by his followers. Kropotkin argues that power, flexibility, agility, speed, endurance and cunning are properties that can improve the chances of survival of a species in certain situations, but that gregariousness and mutual aid are an advantage in the struggle for existence in all cases. "Therefore, while fully admitting that force, swiftness, protective colours, cunningness, and endurance to hunger and cold, which are mentioned by Darwin and Wallace, are so many qualities making the individual, or the species, the fittest under certain circumstances, we maintain that under any circumstances sociability is the greatest advantage in the struggle for life. Those species which willingly or unwillingly abandon it are doomed to decay; while those animals which know best how to combine, have the greatest chances of survival and of further evolution, although they may be inferior to others in each of the faculties enumerated by Darwin and Wallace, save the intellectual faculty" (Kropotkin 1914: 68).

Competition would be an exception from the rule in the animal world during hard times. Better conditions would result from the overcoming of competition by mutual aid. "The animal species, in which individual struggle has been reduced to its narrowest limits, and the practice of mutual aid has attained the greatest development, are invariably the most numerous, the most prosperous, and the most open to further progress. The mutual protection which is obtained in this case, the possibility of attaining old age and of accumulating experience, the higher intellectual development, and the further growth of sociable habits, secure the maintenance of the species, its extension, and its further progressive evolution. The unsociable species, on the contrary, are doomed to decay" (Kropotkin 1914: 266).

Today more and more scientists argue that co-operation is not only a phenomenon within certain species in the animal world, but also occurs between different species (Augros/Stanciu 1992, Carroll/Loye 1992, Sagan/Margulis 1992). "Symbiosis - the living together in intimate association of different kinds of organisms - is more than an occasional oddity. It is a basic mechanism of evolutionary change" (Sagan/Margulis 1992: 123). Examples include algae producing food for and recycling the waste products of the flatworm, symbioses of algae and fungi, blind shrimps that are led around by sighted fish, plants that are pollinated by insects, cows and other ruminants that grass with the aid of gut bacteria, barnacles

\footnotetext{
2 The steady journeys of birds can be considered as the result of the collective experience of a swarm.
} 
attached to whales, anemones attached to crabs, tickbirds cleaning rhinoceros, egrets cleaning cattle, bacteria that regenerate the human intestines. Augros and Stanciu (1992) argue that peaceful coexistence and co-operation between species and among the same species are main evolutionary mechanisms.

Thomas Malthus said that only the physically strong survive and that overpopulation results in struggle for existence. Herbert Spencer based his ideas on Malthus' and argued that human progress is based on competition for limited resources and the survival of the strongest and most intelligent. The unemployed and the poor would have no natural right to survive, there should be no welfare and help for the needy. "The process of "natural selection," as Mr Darwin called it, co-operating with a tendency to variation and to inheritance of variations, he has shown to be a chief cause (though not, I believe, the sole cause) of that evolution through which all living things, beginning with the lowest and diverging and re-diverging as they evolved, have reached their present degrees of organization and adaptation to their modes of life. So familiar has this truth become that some apology seems needed for naming it. And yet, strange to say, now that this truth is recognized by most cultivated people now that the beneficent working of the survival of the fittest has been so impressed on them that, much more than people in past times, they might be expected to hesitate before neutralizing its action now more than ever before in the history of the world, are they doing all they can to further survival of the unfittest!" (Spencer 1884: 3.40). Advocates of welfare wouldn't see that there is no natural right of survival for the poor, one should "allow the struggle for existence to bring on the unworthy the sufferings consequent on their incapacity or misconduct" (Spencer 1884: 3.44$)$

Spencer published his main ideas some years before Darwin, "social Darwinism preceded Darwin" (Aggros/Stanciu 1992: 132). So social Darwinism that heavily influenced racist, eugenic and fascist ideologies was not just a result of a false inference from biology to the social sciences, it was a typical expression and manifestation of early capitalist principles in the intellectual realm. Crude capitalism promotes competition and struggle between companies and individuals for profits and jobs and fetishises competition and exploitation as natural human behaviour. Socialisation and education in the Western world are based on the assumption that these phenomena belong to the essence of the human being, are selfevident and should be taken for granted. The naturalisation of competition and exploitation is an ideology that serves dominant interests. Augros and Stanciu argue "it seems natural to persons shaped by modern Western culture to project their lived experience of struggle onto nature. The imagined war of every organism against every other, then, represents a profound enculturation of science, prejudicing theories and even obscuring the facts. ... The evidence, however, clearly shows that nature is not competitive, but cooperative" (Aggros/Stanciu 1992: 134). Malthus, Spencer, Darwin and the followers of Darwin were socialised in this capitalist environment, their thinking was biased by positively assessing competition. The sciences of the $20^{\text {th }}$ century have produced evidences that seem to indicate that also co-operation is a fundamental feature of both the natural and the social world.

Society is the most complex self-organizing system that we know today. It differs from physical and biological systems in a number of qualities. For pointing out aspects of societal co-operation, it is first necessary to outline some foundations of a theory of social self-organization (for more details cf. Fuchs 2001b, 2002b-f, i-k, 2003a, Fuchs/Hofkirchner/Klauninger 2001, Fuchs/Schlemm 2002, Fuchs/Stockinger 2002, Hofkirchner/Fuchs 2003).

\section{Information and Self-Organisation in Society}

Human beings differ from their animal ancestors and other animals qualitatively. Constitutive for the qualitative difference of the way of organising life has been that human beings e.g. for scavenging no longer simply used means (stick) for achieving immediately given ends (catching of a fruit on a tree), but that they also produce and preserve the means independent from immediate means, i.e. indirect precaution, production and preservation (Fuchs/Schlemm 2002). Such a reversal of ends and means has (thus far?) only taken place once on planet earth, namely by the pre-human becoming human. Humans 
begin to distinguish themselves from animals by starting to produce their means of subsistence by which they are indirectly producing their actual material life.

Man like animals lives from inorganic nature, he must remain in a continuing physical dialogue with nature in order to survive. Animals produce only their own immediate needs, only when immediate physical need compels them to do so. Man produces universally, even when he is free from physical need. Animals only produce themselves; man reproduces and re-creates nature and himself. In the production of his life, which includes the metabolism between society and nature and societal reciprocity, man as the universal, objective species-being produces an objective world and reproduces nature and his species according to his purposes. All generally known specific characteristics of the human being such as consciousness, language and labour are based on this "breakage of immediacy". With the "breakage of immediacy" emerged a new form of socially mediated activities, the societal form of mediation of the life process. This means for the single individual that the maintenance and development of his/her life is no longer only confined to biological processes (including the ones of societal realms), but takes place within societal structures. No human being can live without this mediation by society because his/her individual-cognitive abilities can only develop in mutual relationship with societal conditions.

Functionalist and structuralistic sociological positions are unable to see human beings as reasoning, knowledgeable agents with practical consciousness and argue that society and institutions as subjects have needs and fulfil certain functions. This sometimes results in views of a subjectless history that is driven by forces outside the actors' existence that they are wholly unaware of. The reproduction of society is seen as something happening with mechanical inevitability through processes of which societal actors are ignorant. Functionalism and structuralism both express a naturalistic and objectivistic standpoint and emphasise the pre-eminence of the societal whole over its individual, human parts. Mechanistic forms of structuralism reduce history to a process without a subject and historical agents to the role of supports of the structure and unconscious bearers of objective structures.

In individualistic social theories structural concepts and constraints are rather unimportant and quite frequently sociality is reduced to individuality. There is a belief in fully autonomous consciousness without inertia. Individualism doesn't see the necessarily societal and material interdependence of individuals and doesn't grasp their process of development because it limits itself to advise them that they should proceed from themselves. In Hegelian terms, individualism reduces society to individual being-in-itself or abstract, pure-being, whereas structuralism and functionalism consider the role of the human being in society merely as being-for-another and determinate-being. Only dialectical approaches to society consider the importance of both aspects, unity as being-in-and-for-itself.

The individual is a societal, self-conscious, creative, reflective, cultural, symbols- and language-using, active natural, labouring, producing, objective, corporeal, living, real, sensuous, anticipating, visionary, imaginative, expecting, designing, co-operative, wishful, hopeful being that makes its own history and can strive towards freedom and autonomy (see Fuchs 2002b, c).

In the societal production of their existence, humans inevitably enter into definite relations, which are partly dependent and partly independent of their will. By societal actions, societal structures are constituted and differentiated. The structure of society or a societal system is the totality of behaviours. A specific structure involves a certain regularity of societal relationships that make use of artefacts. Societal structures don't exist externally to, but only in and through agency. In formations such as capitalism societal structures are alienated from the human being and the human being is estranged from the structures because certain groups determine the constitution and development process of these structures and exploit others for facilitating these processes. Alienated societal structures still exist only in and through agency, but some groups have privileged access to and control of these structures, whereas it is much harder for others to influence them according to their own needs and interests. Societal structures in alienated societies are an object and realm of struggle.

By interaction, new qualities and structures can emerge that cannot be reduced to the individual level. This is a process of bottom-up emergence that is called agency. Emergence in this context means the appearance of at least one new systemic quality that cannot be reduced to the elements of the system. So 
this quality is irreducible and it is also to a certain extent unpredictable, i.e. time, form and result of the process of emergence cannot be fully forecasted by taking a look at the elements and their interactions. Structures also influence individual actions and thinking. They constrain and enable actions. This is a process of top-down emergence where new individual and group properties can emerge. The whole cycle is the basic process of systemic societal self-organization that can also be called re-creation because by permanent processes of agency and constraining/enabling a system can maintain and reproduce itself (see fig. 2). It again and again creates its own unity and maintains itself. Societal structures enable and constrain actions as well as individuality and are a result of actions (which are a correlation of mutual individuality that results in sociality).

Re-creation denotes that individuals that are parts of a system permanently change their environment. This enables the system to change, maintain, adapt and reproduce itself. What is important is that the term re-creation also refers to the ability of all humans to consciously shape and create systems and structures, an ability that is based on self-consciousness and, in Anthony Giddens' terminology, the reflexive monitoring of action. Societal systems are re-creative ones because they can create new reality; the sociocultural human being has the ability to create the conditions for his further evolution all by himself. Creativity means the ability to create something new that seems desirable and helps to achieve defined goals; it's a central feature of communicative action (see Fuchs/Stockinger 2002). Man can create images of the future and actively strive to make these images become reality. Individuals can anticipate possible future states of the world, society as it could be or as one would like it to become; and they can act according to these anticipations. Man has ideals, visions, dreams, hopes and expectations that are based on the ability of imagination which helps him to go beyond existing society and to create alternatives for future actions. Based on creativity, man designs society: Design is a future-creating human activity that goes beyond facticity, creates visions of a desirable future and looks for a solution to existing problems. Design creates new knowledge and findings. Man designs machines, tools, theories, societal systems, physical entities, nature, organisations etc. within societal processes. Such an understanding of design as a fundamental human capability (Banathy 1996) takes into account man's ability to have visions and utopias and to actively shape society according to these anticipated (possible) states of the world. It is opposed to an understanding of design as a hierarchical process and as the expert-led generation of knowledge about the world and solutions to problems. Desires, wishes, anxieties, hopes, fantasies, imaginations play an important role in society and hence one should also stress the subjective, creative dimension in the constitution of human and societal experience. Ernst Bloch (1986) has shown that hopes and utopias are fundamental motives in all human actions and thinking. These are also important differences between animals and humans.

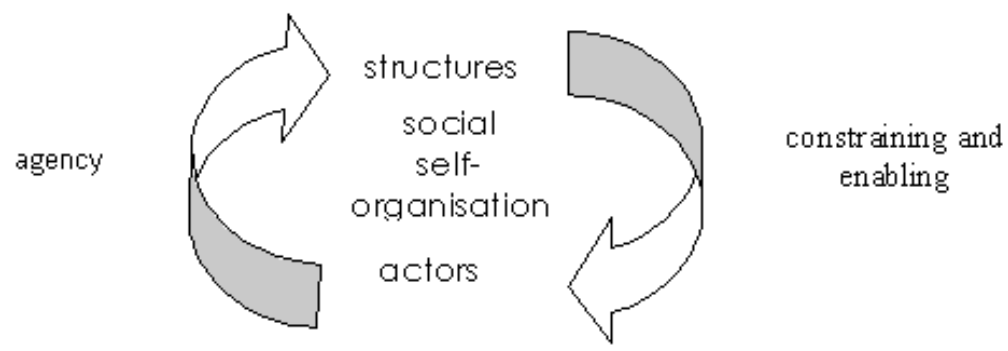

Figure 2. The self-organization/re-creation of societal systems ${ }^{3}$

Terming the self-organization of society re-creation acknowledges as outlined by Giddens the importance of the human being as a reasonable and knowledgeable actor in sociology. Giddens himself has stressed that the duality of structure has to do with re-creation: "Human social activities, like some self-

\footnotetext{
3 This model of social self-organization was first introduced in Hofkirchner (1998a) and elaborated in a number of further works: Fuchs/Hofkirchner/Klauninger (2001), Fuchs 2002b-f, i-k, 2003a)
} 
reproducing items in nature, are recursive. That is to say, they are not brought into being by social actors but continually recreated by them via the very means whereby they express themselves as actors" (Giddens 1984: 2). Saying that society is a re-creative or self-organizing system the way we do corresponds to Giddens' notion of the duality of structuret because the structural properties of societal systems are both medium and outcome of the practices they recursively organise and both enable and constrain actions (for the relationship of Giddens' theory of structuration and social self-organization see Fuchs $2002 d$, i). Social systems and their reproduction involve conscious, creative, intentional, planned activities as well as unconscious, unintentional and unplanned consequences of activities. Both together are aspects, conditions as well as outcomes of the overall re-creation/self-reproduction of social systems.

The mutual relationship of actions and structures is mediated by the habitus, a category that describes the totality of behaviour and thoughts of a societal group (for the importance of Pierre Bourdieu's conceptions such as the habitus for a theory of social self-organization see Fuchs 2002e). The habitus is neither a pure objective, nor a pure subjective structure; it means invention (Bourdieu 1977: 95, 1990b: 55). In society, creativity and invention always have to do with relative chance and incomplete determinism. Social practices, interactions and relationships are very complex. The complex group behaviour of human beings is another reason why there is a degree of uncertainty of human behaviour (Bourdieu 1977: 9, 1990a: 8). Habitus both enables the creativity of actors and constrains ways of acting. The habitus gives orientations and limits (Bourdieu 1977: 95), it neither results in unpredictable novelty nor in a simple mechanical reproduction of initial conditionings (ibid.: 95). The habitus provides conditioned and conditional freedom (ibid.: 95), i.e. it is a condition for freedom, but it also conditions and limits full freedom of action. This is equal to saying that structures are medium and outcome of actions. Very much like Giddens, Pierre Bourdieu suggests a mutual relationship of structures and actions as the core feature of human social systems. The habitus is a property "for which and through which there is a social world" (Bourdieu 1990b: 140). This formulation is similar to saying that habitus is medium and outcome of the social world. The habitus has to do with practices, it not only constrains practices, it is also a result of the creative relationships of human beings. This means that the habitus is both opus operatum (result of practices) and modus operandi (mode of practices) (Bourdieu 1977: 18, 72ff; 1990b: 52).

Social self-organization in the broad sense of re-creation takes place permanently in social systems. There are different types of re-creation that describe how social self-organization takes place. Talking about self-organization on a more concrete level of social analysis requires us to take into account actually existing power structures, classes, class struggle and the relationship of heteronomy and selfdetermination. Co-operation in a very broad sense can be understood as co-action: two or more social actors (individuals or groups) act together in a co-ordinated manner (whatever the subjective reason and motivation for this action might be) and a new social property emerges. Understood in such a broad sense, co-operation is a necessary condition for the existence of society and social systems.

Re-creative systems, i.e. social systems, have the capacity to transcend themselves. Signs appear as, so to say, "not-yets". On this level self-organization produces what can be termed social information. The word "social" in the term social information denotes that such a form of information is constituted in the course of social relationships between several (collective or individual) actors. We consider the scientific-technological infrastructure, the system of life-support elements in the natural environment and all else that makes sense in a society, i.e. economic dispositions, political decisions, and the body of cultural definitions like norms and values, knowledge and rules to be social information (Fuchs/Hofkirchner/Klauninger 2001). All of them are constituted in the course of social actions. Individuals must have a common view of reality; this is the basis for their social interactions and social actions. As a result of their interactions in social systems, social information emerges as a macroscopic structure. Acts of co-operation are mediated by acts of communication that, in turn, are mediated by acts of cognition. Individuals or collective actors act in such a way that they trigger associations and actions of other individuals. They co-ordinate their actions in such a manner that they produce a common social

\footnotetext{
4 "According to the notion of the duality of structure, the structural properties of social systems are both medium and outcome of the practices they recursively organise" (Giddens 1984: 25) and they both enable and constrain actions (26).
} 
information structure. The production of social information is the result of co-action, i.e. co-operation understood in a broad sense. Social information enables and constrains co-action; co-action is based on existing social information/structures and produces new information/structures. Co-action is an inherently productive process, this productivity is not confined to the economy, and it involves economic, political, cultural, technological and ecological aspects.

Information has subjective as well as objective aspects in society. It is on the one hand a property and product of cognitive systems, a difference that makes a difference, and as such it is selected in the communicative process, which can be considered as Niklas Luhmann (1995) has shown as an emergent synthesis of three selections (selection of information, uttering and understanding). Due to the selectivity of the communication process, information has a certain degree of uncertainty. On the other hand information is also an objective, reflective social relationship: If actors communicate, information exists as an objective relationship between them and this relationship involves reflection. Reflection (Widerspiegelung) doesn't mean the mechanical reproduction of data by a receiver; it only means that in the case of communication there is a reaction of one communication partner to the symbolic actions of the other partner. It is determined that he reacts and in this reactions he makes use of symbols, otherwise one couldn't speak of communication. But it is not determined how he will react, this is relatively open, but frequently also to a certain extent predictable due to certain regularities and standardised modes of behaviour that can be found in the social world. Such reflective reactions are neither completely determined, nor completely undetermined, their causality can be characterised as relative chance and incomplete determinism. Such objective information relationships occur milliards of times per day relatively stable, hence information as a social relationship is relatively probable. However there are degrees of uncertainty due to different dispositions, norms, values, habitus, cultural contexts, interpretative schemes, tastes, life-styles etc. of the partners in a communicative setting.

Structures are totalities of durable and institutionalised behaviour. They can be found in all subsystems of society. Structures mediate communications and (co-)actions, they are medium and outcome of (co-) actions and communications. Structures are social relationships and a type of information in society. Social information is a communicative relationship between actors where artefacts are included in order to produce sense and achieve goals. Knowledge as an organised form of data that are interpreted, assessed, and compared, is contained in social artefacts. Artefacts store dead labour and knowledge about society. Social structures are media of society because they mediate social actions and communications. They store and fix knowledge and hence they simplify actions and communications because the foundations of these processes don't have to be produced permanently, they can be achieved by making use of structures. Hence by storing knowledge, social structures reduce social complexity. Structures are carriers of knowledge, they are the foundation of temporal and spatial extension of social systems. Social structures make possible a continuity of social reproduction across space and time; they result in the temporal and spatial distanciation of social relationships without the loss of continuity. Structures also produce specific forms of contiguousness and hence they dissolve distances by re-embedding social relationships that are disembedded in space-time. Social structures are a foundation of action and communication, they enable a certain degree of mobility, they mediate, organise, and co-ordinate social relationships and communications.

Anthony Giddens argues that there are storage capacities in society which enable the existence of institutional forms which persist across generations and shape past experiences that date back well beyond the life of any particular individual (Giddens 1981: 35, 39, 94f, 144, 157-181; 1984: 180-185; 1985: $13 f, 172-197)$. Allocative and authorative resources can be stored across time-space distances. Storage of authorative resources involves the retention and control of knowledge. In non-literate societies the only "container" storing knowledge were human memory, tradition and myths. Writing and notation have allowed a certain time-space distanciation of social relationships. Other forms of storing that have followed and have caused further time-space distanciation are cities, lists, time-tables, money, money capital, nation-states, communication and transportation technologies in general and especially the rapid-transit 
transportation and electronic communication technologies (including electromagnetic telegraph, telephone and computer mediated communication).

Also the brain contains and stores knowledge, communication means a comparison of knowledge, norms, values, ideas etc. Knowledge of actors is contained in the social relationships they enter. Communication means information production, but this information can be assessed as being useful or not. By the mutual mediation of knowledge, new knowledge can emerge in a creative process. Social information relationships contain permanent flows of knowledge between actors; these flows can become productive ones. Such a production process results in the differentiation of the cognitive knowledge structures of the involved actors. Each day we enter multiple information relationships that don't affect our knowledge, but other experiences, relationships and communications change our knowledge, views, norms, values, interpretative schemes etc. In such a case, knowledge flows are considered as meaningful; an information relationship gains a productive dimension.

Information exists in all social relationships, but it has different effects. We neither photographically and mechanically map knowledge, nor are we autonomous knowledge producers. Due to certain normative dispositions certain reactions and interpretations to a stimulus are more probable than others. But the human being is a being that can change his views during productive discourses, hence social information relationships not only increase the knowledge of a subject, they also result in a (faster or slower) differentiation of definitions. Human interpretation is neither mechanical mapping, nor coincidental construction, but constructive reflection (konstruktive Widerspiegelung). Reflection involves reaction to external stimuli during the course of communications where different alternative interpretations and behaviours are possible. It depends on the degree of participation and democratisation of society to which extent interpretation and critical reflection are activated.

Information as reflection in physically self-organizing, i.e. dissipative systems has a low degree of autonomy, there is a simple reaction to stimuli. In autopoietic, biologically self-organizing systems, information production also has to do with interpretation and the selection of certain reaction. Information here not only has syntactic aspects, but also semantic ones and there is a larger degree of freedom than in dissipative systems. The evolutionary systems with the highest degree of freedom are socio-culturally selforganizing, i.e. re-creative systems. Here the ability of creating new realities and environments is important, like in physical and biological information is produced as a reaction to stimuli, but there are certain meaningful interpretations and based on these foundations practical actions and communications are consciously selected. In social systems, information has practical effects onto the environment; it involves creativity, norms, values and the selection of behaviours and communications. These are phenomena of pragmatics; pragmatics is an aspect of social information that distinguishes it from physical and biological information.

Social structures store information about society. Hence there are also certain categories that can be termed social information. In re-creative, i.e. social systems, self-organization produces what can be termed social information: The word "social" in the term social information denotes that such a form of information is constituted in the course of social relationships of several individuals. According to Max Weber a social relationship is established if an interrelated reference exists between two actors. Social acting is orientated on meaningful actions of other actors. Social actions are a necessary condition of a social relationship, but not a sufficient one because social acting doesn't necessarily require the actors to mutually refer to each others actions: One actor can refer to the actions of another without the latter referring to those of the first.

At a first glance (see figure 3), you can distinguish three main spheres that form the layers of hierarchical social systems: the technosphere is dominated by the ecosphere and the ecosphere by the sociosphere. The technosphere is the sphere in which human beings are active in innovating and applying scientific-technological tools in the course of social life. An infrastructure of tools, methods and capabilities that comprise the overall forces of the socially living humans is the base of re-creative systems and at the same time the simplest quality of social information. The ecosphere is the sphere in which human beings

\footnotetext{
5 This model was first introduced in Fuchs/Hofkirchner/Klauninger (2001)
} 
work, in other words, where they use their tools, methods and capabilities to adapt nature to themselves in order to survive and construct an umwelt, where they objectify the life-support conditions of nature and appropriate nature to assure themselves life support. The natural environment in its character of providing life support is another product of re-creative systems and another quality of social information. The sociosphere as a whole is the sphere in which human beings perform social actions. Here they constitute what makes sense to them and realise it. Sense is then another one of the higher qualities brought forth by the re-creation of social systems and social information.

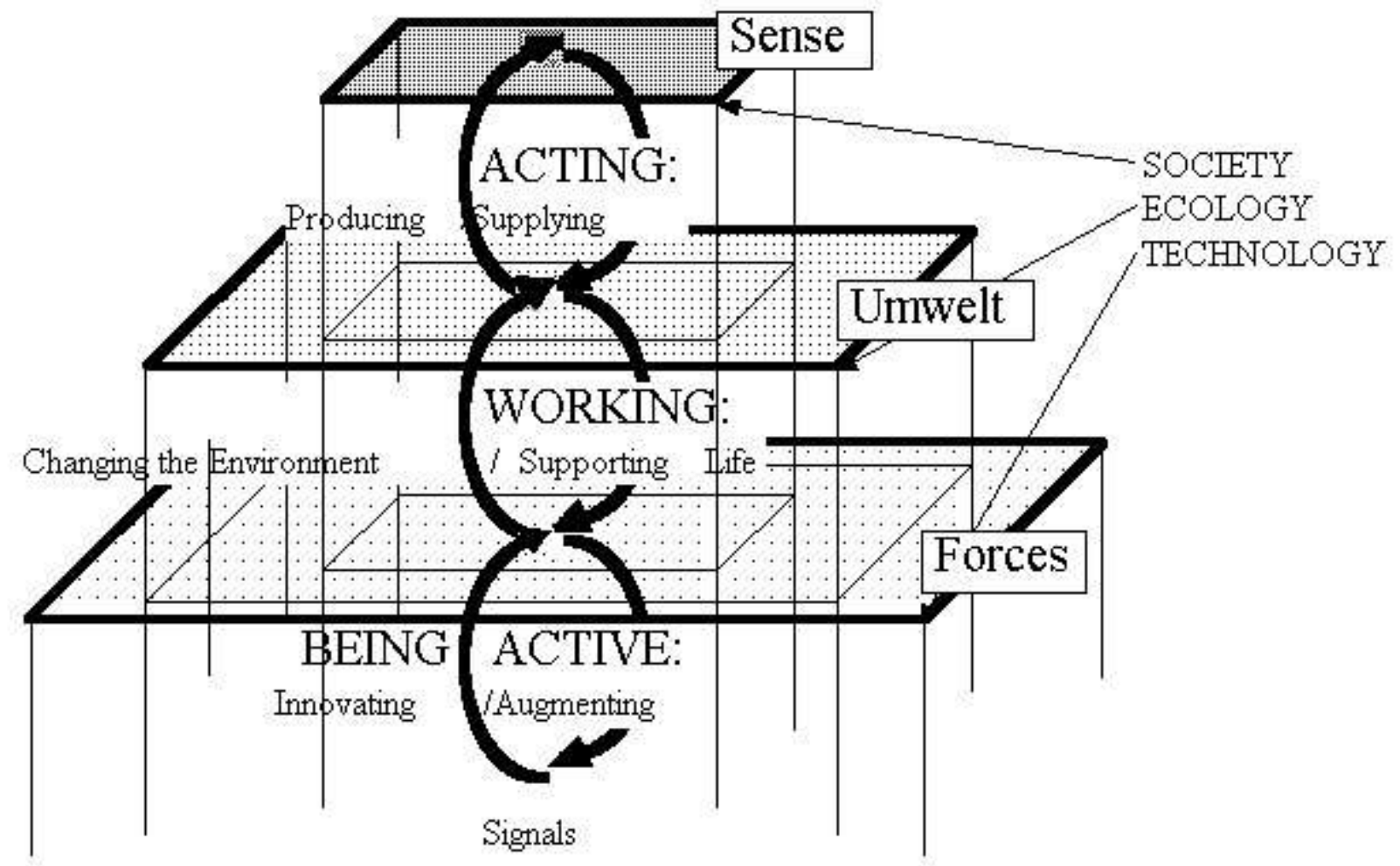

Figure 3:The Generation and Differentiation of Social Information by Co-Action, Part I

Upon closer scrutiny, the constitution and realisation of sense can be differentiated further. Usually economy, politics and culture are the realms in which sense is produced by social actions.

In short, in all social systems there are three manifestations of information (see figure 4): dispositions over resources, decisions on life conditions that form regularities of the living together and definitions of rules like norms/values. They store information about past social actions and simplify future social situations because by referring to social information the basics of acting socially do not have to be formed in every situation of this kind. Social information serves as a durable foundation for social actions, even though it changes dynamically. It can be found in all subsystems of society - economy, politics and culture.

In the economic realm, the human being deals with the production, distribution and allocation of use values and resources. The foundation of each economic process is formed by productive forces which combine the living labour force system, that is, physical ability, qualification, knowledge, abilities, experience, as well as technology, science, amount and efficacy of the means of production, and organisational factors, with natural ones that are due to the umwelt. The disposition of resources that appear as property relations can be seen as social information on the economic level. Economy means a dual process of production and allocation. Material resources that are vital to society are produced by

${ }^{6}$ cf. Fuchs/Hofkirchner/Klauninger (2001) 
making use of the system of productive forces. On the other hand, resources are utilised in order to ensure the preservation of the members of society in a process of allocation of economic goods.

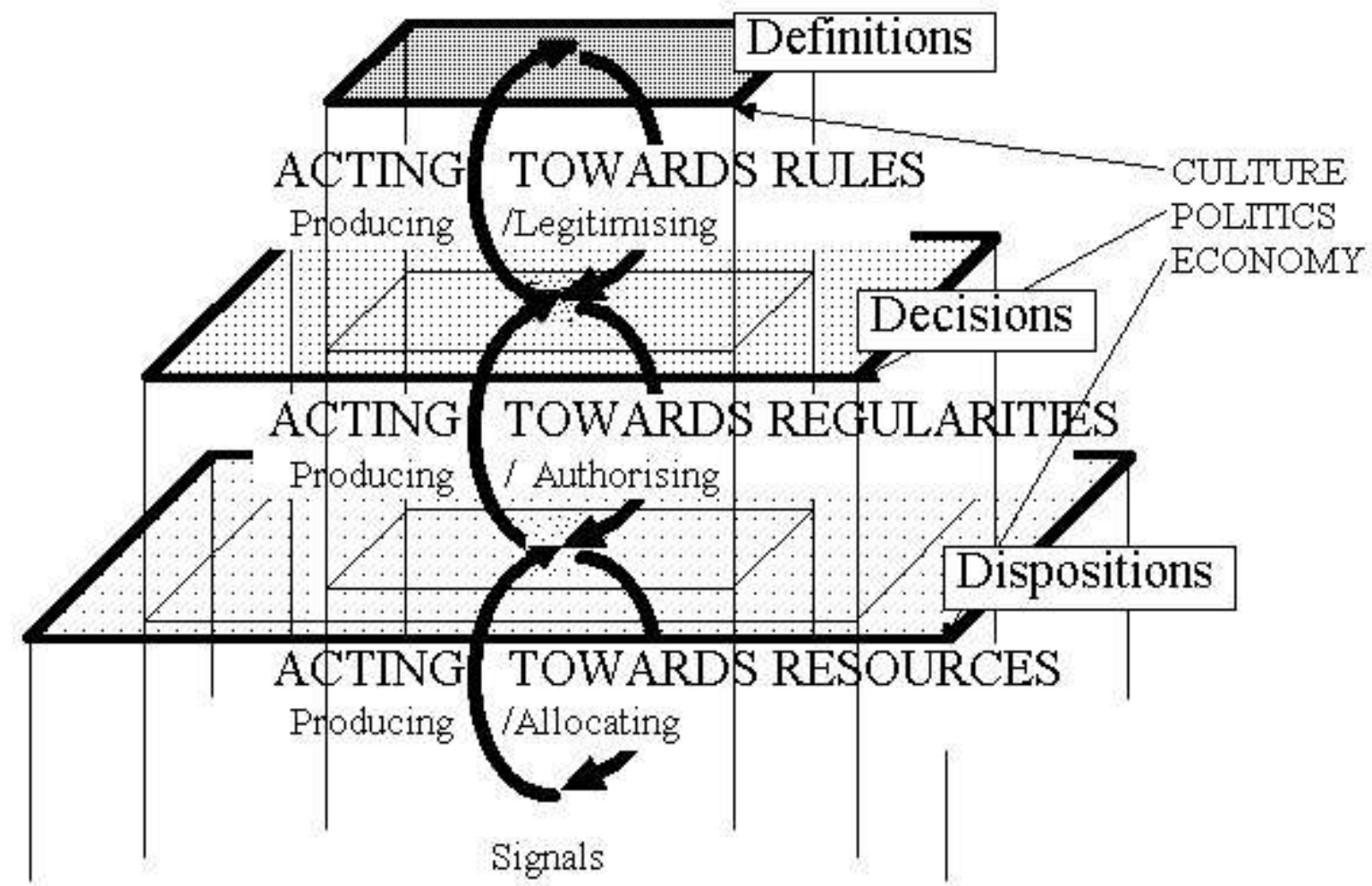

Figure 4: The Generation and Differentiation of Social Information by Co-Action, Part II

Production and reproduction can be seen as the material foundation of each type of society. Such a materialist view is not a reductive one if one considers that though the political and cultural superstructures depend on economic processes they work nevertheless in relative autonomous ways and influence the economy in processes of downward causation as well. All of them are dialectically related because economic influences on politics and culture can cause the emergence of new political and cultural phenomena, and cultural and political influences on economy can cause the emergence of new economic phenomena.

Politics deals with decisions that refer to the way life conditions are set (including how economic resources are being used and how they are distributed). The decisions that are being reached in a social and communicative way in the area of politics turn out to be just another type of social information. Politics encompasses a dual process of decision-making and authorisation of actions: Decisions are made on the basis of available resources in order to assure the functioning of society. These decisions either take on coded or non-coded forms. Once a decision is reached the next step is to execute it. And executing decisions always means that members of society are authorised to act in a particular manner. In political relationships it is determined how power is constituted, distributed, allocated and disposed, decision power is social information in politics. Power can be defined as the disposition over the means required to influence processes and decisions in one's own interest, domination refers to the disposition over the means of coercion required to influence others or processes and decisions. Domination always includes sanctions, repression, threats of violence and an asymmetric distribution of power. Power can't be abolished; it is a fundamental property of all social systems. It's decisive how power is distributed.

Culture can be seen as the subsystem of society in which ideas, knowledge, social norms, and social values are defined within the framework of habits, ways of life, traditions, and social practice. The emerging definitions are a type of social information that comes into existence in the area of culture. 
Culture encompasses a dual process of defining the rules and being legitimised by observing the rules. On the one hand social norms, values, knowledge, ethics and morals are constituted and differentiated in relation to decisions already reached. On the other hand, social norms legitimise acts of the members of society. The type of participation determines if at all, how, and to which degree individual actors and social groups can influence definitions that affect them.

Based on these foundations I will now point out some aspects of co-operation in society. Cooperation can be understood both in a broad sense of social action and in a narrower sense of mutually benefiting social actions.

\section{Co-action and Co-operation in Society}

I first want to point of a broad understanding of co-operation as co-action. Social information emerges by co-actions. Co-action takes place in the technosphere, the ecosphere and the sociosphere (economy, politics, culture). Co-action is equivalent to social action. There are a number of general characteristics of co-action:

- Co-action is a productive process, something new emerges from social relationships of several (individual or collective) actors

- Co-action is recursively linked to social structures. Social structures enable and constrain co-action, they are a foundation, a medium as well as an outcome of co-action.

- Co-action is based on cognition and communication. Subjective, cognitive processes are externalised and co-ordinated in such a way that communication takes place within social relationships. These communicative actions are productive; by co-action new social properties emerge.

- Co-action frequently, but not necessarily involves temporal and spatial presence of all involved actors. Social structures such as modern technology allow a certain degree of time-space distanciation of social relationship. As a result co-action can be achieved across temporal and spatial distances, technologies support the disembedding and reembedding of co-action. Specific technologies have been developed for this support, so-called Computer Supported Co-operative Work (CSCW)applications.

- Co-action can be based on various, differing motivations of the actors. It can be motivated altruistically (costs for the agent, benefits for the others), reciprocally (balance of costs and benefits for all agents), mutually (benefits for all agents), competitively (benefit for the agent due to costs for others)

- In co-action, the action (meaningful behaviour) of one actor is oriented on the actions of other actors. However not all actors must be conscious of this orientation, there can be a certain degree of unconsciousness. E.g. someone might publish a book that helps someone else to better cope with his life. Although the writer might not have had such a subjective intention and might not be aware of the effects, his poem in a process of co-action improves the life situation of another person. There are both conscious and unconscious (i.e. unintended, unknown) consequences of actions.

- Co-action produces certain emergent outcomes; these results are not automatically morally good ones. E.g. two people might co-act in order to kill someone whom they both hate; others might co-act in order to help the needy.

Concerning the causality of co-action we can distinguish different approaches. The two classical ones are the mechanistic and the holistic one. Mechanistic positions assume that co-action is a fully rationally planned, intended action and that all aspects and effects of co-action can be forecast. Holistic positions assume that co-action occurs fully spontaneously, unplanned, unconsciously, accidentally and that all of its aspects and effects are fully unpredictable. My own view reflects a dialectical unity of the two classical approaches that tries to go beyond them. 
A mechanistic approach to co-operation is put forward by rational choice theory. James Coleman (1990) sees society as the result of goal-oriented actions of autonomous actors. Rational choice theory argues that individuals have full freedom of action and make decisions due to rational calculations. They select alternatives that are considered as optimal due to a scheme of preferences. It is assumed that actors make use of the resources they control in order to achieve their goals.

Rational choice theory argues atomistically and mechanistically. Individual interests are seen as predisposed entities, not as resulting from social power relationships. Coleman argues that each resource has a certain value:

$$
v_{k}=\sum_{i=1}^{n} x_{k i} r_{i}
$$

$\mathrm{n}$ : number of actors

vk: value of resource number $\mathrm{k}$

$x k i$ : interest of actor $\mathrm{i}$ in resource $\mathrm{k}$

ri: relative power of actor $\mathrm{i}$

$$
\mathrm{r}_{\mathrm{i}}=\sum_{\mathrm{k}=1}^{\mathrm{m} \mathrm{C}_{\mathrm{ik}} \mathrm{v}_{\mathrm{k}}}
$$

$\mathrm{m}$ : number of resources

$\mathrm{C}_{\mathrm{ik}}$ : actor i's degree of ownership of resource $\mathrm{k}$

\begin{tabular}{|l|l|}
\hline Approaches to Co-action & Causality of Co-action: \\
\hline Mechanistic Approaches & $\begin{array}{l}\text { rationally planned, conscious, } \\
\text { intended, predictable, } \\
\text { necessity }\end{array}$ \\
\hline Holistic Approaches & $\begin{array}{l}\text { spontaneous, unplanned, } \\
\text { unconscious, unintended, } \\
\text { unpredictable, chance }\end{array}$ \\
\hline Dialectic Approaches & $\begin{array}{l}\text { unity of rational planning and } \\
\text { spontaneous emergence, } \\
\text { unity of conscious and } \\
\text { unconscious aspects and } \\
\text { consequences, unity of } \\
\text { necessity and chance }\end{array}$ \\
\hline
\end{tabular}

Table 1: Approaches to co-action

In rational choice theory, interaction is conceived as exchange of resources between autonomous actors. This exchange is conceived as antagonistic co-operation because on the one hand all actors are interested in exchange, but on the other hand they have the interest to benefit from the exchange more than others.

Coleman (1990) argues that trust and co-operation is based on rational calculation, actors would measure possible advantages and disadvantages that could arise. The trustor expects positive behaviour from the trustee, due to his expectations he enables resource-based advantages for the trustee and expects the trustee to behave in such a way that in the end he also has resource-based advantages. Coleman argues that a mathematical calculation is done by an actor who is expected to trust someone:

The actor enters a relationship of trust/co-operation if he expects that the possibility and amount of gain is larger than the possibility and amount of loss:

co-operation if

$p /(1-p)>L / G$

no co-operation if

$p /(1-p)<L / G$

$p=$ possibility of winning resources 


\author{
$1-p=$ possibility of loosing resources \\ L: potential loss \\ G: potential gain
}

Coleman says that actors always act in a manner from which they expect winning resources. Cooperation and trust would be purely rational considerations and motivated by self-interest. Coleman doesn't see that there are unconscious and unintended consequences of actions and that rules, norms and values can motivate actors to behave in non-egoistic and altruistic ways. Morality and emotional commitment run counter to purely rational considerations. Coleman wrongly assumes a value consensus that is based on the acceptance of a market- and exchange-model of interaction. In the real world there are numerous struggles and conflicts due to differing values. Social relationships are numerous and complex, hence not all aspects of social life can be perfectly planned.

Holistic approaches stress the spontaneity of co-operation and that co-operation can't be planned or calculated. Robert Axelrod (1984) assumes that co-operation can and does emerge in a world of selfinterested, egoistic actors. Necessary conditions for achieving co-operation would be a good chance of continuing interaction, i.e. a sufficiently large chance to meet again. If this is the case, co-operation could evolve in three stages:

1. Co-operation cannot emerge if the actors virtually have no chance to interact with each other, but it can evolve from small clusters of individuals who base their co-operation on reciprocity and have a small proportion of their interactions with each other.

2. A strategy based on reciprocity can thrive in a world where many different kinds of strategies are being tried

3. Co-operation, once established on the basis of reciprocity, can protect itself from invasion by less cooperative strategies.

Friendship would hardly be necessary for the development of co-operation, there would only have to be a slight degree of reciprocity. Co-operation could even develop between people who don't know each other and between antagonists as e.g. the "live and let live"-system in the trench warfare of World War I shows. "The troops would attack each other when ordered to do so, but between large battles each side would deliberately avoid doing much harm to the other side - provided that the other side reciprocated" (Axelrod 1984: 60). Axelrod's main hypothesis is that "mutual cooperation can emerge in a world of egoists without central control by starting with a cluster of individuals who rely on reciprocity" (ibid.: 69). If this were the case, co-operation would first be started spontaneously, unconsciously or would be unintended. In the trench warfare situations such as bad weather or Christmas resulted in pauses, this unconscious reciprocity resulted in the emergence of conscious co-operative strategies of avoiding killing someone in order to avoid being killed by the opponents. Axelrod stresses the spontaneous and unpredictable emergence of co-operation due to coincidental reciprocity. He says (opposed to rationalistic theories of cooperation) that the co-operating individuals "do not have to be rational: the evolutionary process allows the successful strategies to thrive, even if the players do not know why or how. Nor do the players have to exchange messages or commitments: they do not need words, because their deeds speak for them. Likewise, there is no need to assume trust between the players: the use of reciprocity can be enough to make defection unproductive. Altruism is not needed: successful strategies can elicit cooperation even from an egoist. Finally, no central authority is needed: cooperation based on reciprocity can be selfpolicing" (ibid.: 173f).

An example of the assumption that co-ordination is something unplanned, unconscious and can result from egoism is the invisible hand theorem. Adam Smith describes in his "Wealth of Nations" that as a result of the market-based, egoistic actions of individuals, unintended order and general welfare shows up. All economic actors act according to their self-interests, but welfare would emerge as a sort of invisible cooperative phenomenon. Capitalists would promote general welfare unintentionally by their egoistic 
behaviour. This theorem has been interpreted as a phenomenon of emergence and self-organization. "When Adam Smith wrote of the way that markets lead their participants, 'as if by an invisible hand', to outcomes nobody intended, what was he describing but an emergent property?" (Krugman 1996: 3). Ullrich Witt (1997) argues that economic self-organization consists of self-regulating (negative feedback, stabilises existing structures) and self-augmenting (positive feedback, destabilisation of existing structures, emergence of new structures) mechanisms. The self-regulating instance would be the invisible handtheorem, the self-augmenting one the spontaneous emergence of knowledge.

Peter Weise (1998) argues that self-organization can only result from positive feedback loops. The invisible hand theorem would deal with negative feedback (competition, rivalry), hence one couldn't speak of a phenomenon of self-organization. The invisible hand theorem indeed distorts capitalist reality and its falsification by reality shows that co-operation is not a fully unconscious and unintended phenomenon. General welfare means welfare for all. But in capitalism we rather find a general law of capitalist accumulation that says that capital accumulation increases the affluence of one group relatively by decreasing and degrading the social situation of others relatively. In some cases such as early capitalism this takes even place in absolute terms. This law doesn't mean that there is an automatic tendency of absolute impoverishment in capitalism ${ }^{7}$ because the general wealth can increase absolutely although inequality increases relatively. Today the social gaps between capital and labour, centre and periphery, men and women, workers and the unemployed, domestic citizens and immigrants increase dramatically. The wealth of the ruling and dominating class doesn't according to Marx's labour theory of value stem from an invisible force, this theory seems to prove that it rather results from unpaid surplus labour that is being produced by wage labourers and reproductive workers, from underpaid jobs, precarious working conditions, as well as from the misery and distress of immigrants, the unemployed, the poor and the third and fourth world. It is an essential assumption of the theorem of the invisible hand that corporate egoism results in general welfare. The actual situation of the capitalist world system shows that the assumptions and conclusions of the theorem are wrong.

Both the mechanistic rational choice approach and the holistic approach to co-operation are based on unrealistic assumptions. Social life is complex because individuals enter numerous social relationships and social groups are networked entities. Hence social actions can't be planned fully rationally. On the other hand, the fact that there is a degree of uncertainty in society doesn't mean that all social behaviour occurs fully spontaneously. There are regularised routines in daily life and therefore the possibility that certain actions will take place in a certain expected manner at a certain place and at a certain time is frequently very large. Some aspects of social life are regularised, others involve a high degree of uncertainty. Concerning the evolution of society there are phases of regularised stability and phases of instability.

Intentional activities are necessary for social reproduction, but not all consequences of their actions can be foreseen by the actors, i.e. there are also unintended and unexpected aspects of human activity. A social system has to do with continuity of social activities across time-space. Social systems involve social relationships reproduced across time and space, structures are moments recursively involved in the (re) production of social systems (Giddens 1981: 26). Ordinary life is possible by ontological security that is based on the routinisation of actions and is made to happen by the actors' reflexive monitoring their actions (Giddens 1984: 60-64). The positioning of actors within certain social frameworks and in respect to rules

\footnotetext{
7 Marx formulated the general law of capitalistic accumulation in the following words: "The greater the social wealth, the functioning capital, the extent and energy of its growth, and, therefore, also the absolute mass of the proletariat and the productiveness of its labour, the greater is the industrial reserve army. The same causes which develop the expansive power of capital, develop also the labour-power at its disposal. The relative mass of the industrial reserve army increases therefore with the potential energy of wealth. But the greater this reserve army in proportion to the active labour-army, the greater is the mass of a consolidated surpluspopulation, whose misery is in inverse ratio to its torment of labour. The more extensive, finally, the lazarus-layers of the workingclass, and the industrial reserve army, the greater is official pauperism. This is the absolute general law of capitalist accumulation" (Marx 1867: 673f). This thesis has again and again been interpreted as one of absolute impoverishment. Vulgar interpretations of Marx hold that he said that captital accumulation necessarily increases the number of unemployed and poor people and hence results automatically in a revolutionary transformation towards communism. But in fact Marx is speaking of a relative phenomenon, a relative mass and proportionality. The accumulation of capital results in an increase of the mass of surplus value, surplus labour increases relatively to necessary labour. This means that wages (variable capital) decrease relatively to surplus value. With accumulation the total wealth increases, but the degree of unequal distribution increases relatively. Marx's assumptions have not been falsified, they have rather been verified by today's unequal distribution of wealth, capital and property.
} 
allows the routinisation of actions. The reproduction of society is based on human practices (see Giddens 1984: 26-28, 375f). Actors reflexively monitor their actions, i.e. human behaviour has an intentional and purposive character. But there are also unintended consequences of actions that by the way of causal feedback loops form unacknowledged conditions of further actions.

Knowledgeable human beings make history, but the conditions and possibilities of these changes are conditioned by the existing social structures and the material world. There is dialectic of freedom and necessity in co-action. Self-organizing systems such as society have a non-linear causality: similar causes can have different effects and different causes similar effects; small changes of causes can have large effects whereas large changes can also only result in small effects (but nonetheless it can also be the case that small causes have small effects and large causes large effects). The causality of self-organizing systems can be described as incomplete determinism or relative chance, there is a dialectic of chance and necessity.

What Giddens calls conjuncture refers to the fact that similar results of social development can have quite different causes. With this concept he tries to avoid determinism in the social sciences. It very much resembles the assumption of self-organization theory that causes and effects can't be mapped linearly. Conjunctures understood as interactions of influences that in a particular time and place, have relevance to a given social period (Giddens speaks of "episodes") play an important role in social change (Giddens 1984: 251). Similar results can have quite different causes. "The conjuncture of circumstances in which one process of development occurs may be quite different from that of another, even if their 'outcomes' [...] are similar" (Giddens 1984: 251).

The creative human being is not a pure object of social structures, he has relative freedom of action due to creativity and self-consciousness. In society, creativity and invention always have to do with relative chance and relative indeterminism. Social practices, interactions and relationships are very complex. The complex group behaviour of human beings is another reason why one should assume a degree of uncertainty of human behaviour (Bourdieu 1977: 9, Bourdieu 1990a: 8). Habitus and social structures both enable the creativity of actors and constrain ways of acting. Social behaviour both has planned and spontaneous, conscious and unconscious, necessary and arbitrary aspects. Co-action is neither a mechanical result of social conditions, nor is there a fully free, creative will that is independent of social conditions. In social theory there is a false dilemma between mechanism and finalism (Bourdieu 1977: 72f). This dilemma can also be found in theories of co-operation. A way out of it is dialectical causality that suggests that opposing categories have a certain degree of identity and unity on a higher level. Co-action can be adequately explained by assuming a unity of rational planning and spontaneous emergence, a unity of conscious and unconscious aspects and consequences, and a unity of necessity and chance.

Co-operation is a topic that has been widely ignored in traditional sociologys. Marx defined co-operation as numerous labourers working together side by side, whether in one and the same process, or in different but connected processes (Marx 1867: 344). He was right that co-operation means working together, but this is not only an economic, rather a universal social phenomenon. Co-operation is not confined to a single branch of society, it is a universal principle in all subsystems, including besides the economy also politics, culture, media, education, art etc. Besides that co-operation is today not only a compulsion and something that can solely be found in the industrial labour process, co-operation is a collective process that makes use of the re-creativity of social systems in order to achieve defined goals more efficiently.

Based on co-operation in the wide sense that I have termed co-action, co-operation in a narrower sense can also be found in society. I now want to outline some qualities of this second understanding.

Schmidt/Bannon (1992) argue that mutual dependence is a condition for co-operation: "people engage in co-operative work when they are mutually dependent in their work and therefore are required to cooperate in order to get the work done. [...] Being mutually dependent in work means that A relies positively on the quality and timeliness of B's work and vice versa" (Schmidt/Bannon 1992: 13). They say that co-

\footnotetext{
8 E.g. there is no mentioning of co-operation as an important sociological topic in Giddens (1993) and Haralambos/Holborn (1991), two widely used standard introductory sociological textbooks.
} 
operation always means that a task can't be reached individually. But in reality, some tasks might be reached individually, but actors engage in co-operative relationships because they can achieve goals more efficiently and more quickly together with others who share the same assumptions and goals, although the tasks might also be reached individually. It is not true that necessarily "the reason for the emergence of cooperative work formations is, of course, that workers could not accomplish the task in question if they were to do it individually" (Schmidt/Bannon 1992: 14). Maybe they could accomplish it alone, but they find cooperation more attracting.

Co-operation involves some sort of shared goals and can be accomplished across spatial and temporal distances because modern technologies enable the disembedding and reembedding of social relationships, they cause and overcome time-space distanciation of social relationships, including cooperative social relationships. Co-operation involves mutual learning and mutual aid. Co-operation means social situations and processes where human actors co-ordinate their actions and communications in such a way that the social system makes use of its auto- and re-creativity and creates a new reality that represents a shared goal and a benefit for all involved actors (see also Oberquelle 19919). This result can due to co-operation be reached more effectively and efficiently than in an individual situation. The cooperating actors have to a certain extent shared goals, they agree upon certain conventions and communicate about goals and convention in order to reach a common understanding. Co-operation means that actors communicatively make concerted use of existing rules and resources in order to create new rules and resources. Rules and resources (structures) are medium and outcome of co-operation. By cooperating, actors mutually benefit from each other, i.e. co-operation means communicative settings with positive "symbiotic" relationships.

Co-operation in a weak sense means co-action, i.e. social action. Co-operation in a stronger sense that I would like to emphasise means more than co-action:

- In co-operation the involved actors are mutually dependent.

- All actors benefit from co-operating.

- Co-operating actors have to a certain extent shared goals.

- By co-operating, actors can reach their goals more quickly and more efficiently than on an individual basis.

- Co-operation is based on communication about goals and conventions in order to reach a common understanding.

- In co-operation the actors make concerted use of existing structures in order to produce new structures. Co-operation is based on sharing the existing and the newly produced structures.

- Co-operation involves mutual learning and the common production of new reality.

- Co-operation doesn't mean the absence of conflict, conflict on a non-escalating level can be productive. Controversy can be constructive and conflict creative.

- In co-operative social relationships there is a high degree of networked, interconnected activity. The actors depend on each other. Mutual interconnectivity and mutual responsibility emerge.

Co-operation is based on a shared symbolic system. If this symbolic system as well as the value of using this system commonly is spread throughout society, co-operation will evolve. Francis Heylighen (1992) discusses the evolution of co-operation in terms of "memes" (cognitive or behavioural patterns that can be transmitted from one individual to another one by learning and imitation) and a so-called "metasystem transition" (control system at a meta-level that optimises the actions of the systems at the level below). Individuals carrying the same meme tend to be altruistically towards each other. Meme-based altruism would be typical for human groups able to use language. Language would be a means of spreading memes. Information-sharing by communication would be a foundation of co-operation. Shared information would function as a metasystem in society which co-ordinates and promotes co-operation. By

\footnotetext{
9 "Unter kooperativer Arbeit sollen Arbeitssituationen verstanden werden, in denen mehrere Personen zusammenarbeiten zwecks Erreichung eines Ergebnisses, welches unter den gegebenen Randbedingungen nur gemeinsam, aber nicht einzeln erzielt werden kann".
} 
sharing information/memes a metasystem transition from isolation or competition to co-operation could take place.

Social self-organization/re-creation is based on co-action, co-operative self-organization forms a certain class of co-action and social self-organization that is based on mutual benefits and striving to a certain extent for self-determination of the individual and society. Due to this close connection between selfdetermination and co-operation, it seems feasible to take a closer look at the relationship between selforganization and self-determination.

\section{Self-organization and Self-Determination}

Social self-organization in a broad sense covers the re-production of society in very general terms that apply to all societies and all social systems, but it does not specify how exactly this self-organization of society takes places on a more concrete level. So ascending from the abstract to a more concrete level, one has to distinguish different forms of how society can reproduce itself and aspects of power, domination and class will play an important role. A more thorough look reveals that both co-operation and competition are ways in which modern society reproduces itself.

Self-organization in a broad sense can be understood as re-creation or self-reproduction of society. In a narrower, political sense social self-organization is based on co-operation, participation, self-determination and direct democracy. Subjective theories of social self-organization have in common that they associate an ethical vision of a better society with the notion of social self-organization. They are not so much interested in a functionalist interpretation of the concept that describes how society reproduces itself and how society is, they are interested in visions, utopias and in how society could be. Social self-organization is interpreted in terms of co-operation, participation, direct democracy, respect, solidarity, responsibility and tolerance. These theories (for a more detailed discussion see Fuchs 2002b) argue that

- democracy is an expression of self-organization, dictatorship an expression of heteronomy

- humans are not just auxiliary persons of objective laws, but can and should positively intervene into society, hence they are designers of their future

- self-organization of social system is oriented on making possible the effective and humanistic satisfaction of human need

- the conditions of living should take on forms where all can recognise themselves, determine themselves and realise themselves.

- self-organization also puts forward the notions of responsibility, solidarity and tolerance

- self-organization in terms of self-determination means the possibility for a person to give himself his own law and sense

- there should be active hope for a better society. It wouldn't be decisive if certain actions are successful, but it would be decisive that they can be successful.

- that social self-organization is the principle of bottom-up social-organisation that stimulates the capacity to act

Beyerle (1994) puts forward two concepts of self-organization: an objective, structural one that explains the emergence of social order as a mutual relationship of structures and social actors (he also refers to this as autopoiesis). And a subjective, political concept that distinguishes between heteronomy and selforganization in terms of self-determination. This political concept of self-organization refers to one of three types of organisation: the other two are hierarchy and negotiation-based organisation. Self-organization in this sense refers to the self-regulation of subsystems of society and self-management (or selfadministration) of institutions. He says that heteronomy and self-organization are two principles that supplement each other and are necessary for the evolution and self-maintenance of society. He argues that the development of organisations and social systems at first results in an imbalance of power, "an 
autopoiesis of humans in groups, i.e. the emergence of society, always result in domination of humans by humans. To put it another way: Social autopoiesis results in forms of political heteronomy" (Beyerle 1994: 244). But a concentration of power is challenged which results in a long-term balance of power that is institutionalised in a certain way. In modern society, this is done by the state that creates a balance of heteronomy and self-organization. Beyerle argues that self-organization and heteronomy are not two alternatives, but they complement and require each other. In his view, autopoiesis can take on two different forms (self-organization and heteronomy).

Beyerle's conception of the development of society is a deterministic one because he assumes that forms of heteronomy and domination must emerge in each type of society. He does not see that heteronomy is a historical phenomenon that has come into existence with the beginning of societies that are based on domination. Domination itself is not something that is intrinsic in all societies because if this were the case, one would have to argue anthropologically that competition and domination belong to the (genetic) essence of man. Such arguments reduce complex social phenomena to biology and are an expression of genetic fetishism. Domination and heteronomy are social phenomena and hence they would cease to exist in post-domination-societies that are guided by the principles of self-determination and participation.

Elizabeth Göbel (1998) also distinguishes two types of self-organization: autogenetic self-organization (the spontaneous emergence of rules) and autonomous self-organization. Göbel uses Friedrich August von Hayek's concept of the spontaneous emergence of order for the systemic/autogenetic part of selforganization. She says that this a model opposed to the idea of consciously designing organisations. Order that emerges from itself has not been consciously created, it is unintended, unpredictable, unexpected and forms spontaneously (Göbel 1998: 97). The spontaneous emergence of rules is a slow, evolutionary process. But also whole systems or organisations can spontaneously emerge. The individual that enters such a system, adapts its goals and interests automatically and all by itself to the organisation. Many individuals pursue their goals and hence the order of the whole system emerges spontaneously.

Representatives of neo-liberal ideologies argue that modern organisations cannot be steered (by social groups or the state) and that hence one should not intervene and rather refrain from human intervention. But even liberalised markets and deregulated economic organisations do not function without human intervention in today's neo-liberal capitalism - they depend heavily on state-subsidies and the centralised and monopolised functions of capital that are carried out by economic actors. The largest corporations (especially in the IT-sector) are in fact heavily funded by the state.

Göbel distinguishes between self-organization as systemic autopoiesis and self-organization as selfsteering of actors. She both puts forward the systemic and the subjective concept of self-organization. Autogenetic/systemic self-organization refers to the spontaneous emergence of rules, norms and organisations, autonomous self-organization to a state where members of organisations can determine their own rules. She argues that there are three types of organisations: heteronomous, autonomous (selfdetermined) and autogenetic (self-emerging) ones. Göbel says that autonomous self-organization can be opposed to heteronomy (autonomous complementary self-organization) or co-evolve with heteronomy (autonomous parallel self-organization). She does not clearly point out how the systemic and the subjective type of self-organization are related and she makes the same mistake as Beyerle by saying that heteronomy and (autonomous) self-organization are not necessarily opposing forces. If this relationship were conceived as an opposing one, this would radicalise the concept of social self-organization and it would theoretically withdraw legitimacy from most modern institutions because they are not at all based on self-determination, in fact heteronomy is a fundamental principle of modern, capitalist society that has penetrated all areas of life. Beyerle and Göbel want to stick to the legitimacy of these institutions, hence they argue that heteronomy and self-determination are not opposing forces, but balance and require each other within modern institutions.

The individual as a social being must co-act and co-operate with others to a certain extent in order to exist. Competition is a social relationship in which the social interactions as well as the relationships of power and domination enable some individuals or social sub-systems to take advantage of others. The first 
benefit at the expense of the latter, the latter have to deal with the disadvantages of the situation. Cooperation and competition are two modes of designing social systems, co-operation is necessary at least to a certain extent for society to exist, competition is an artificial mode of shaping social relationships.

Beyerle and Göbel distinguish between a co-operative and a competitive type of social self-organization, but they say that the heteronomous and the democratic type always show up together, complement and require each other and cannot be separated. In my view, such a conception takes out the potentiality for a radical participatory democracy that is put forward by the concept of social self-organization. I would in fact say that in modern society there is an antagonism between co-operation and competition that shows up in all sub-systems of society. Competition imprints all social relationships and does not leave enough room for direct democracy and immediate co-operation. Competition and co-operation are colliding, antagonistic forces that cannot be balanced as in the view of the Tao or modern organisation theory. This antagonistic relationship is a historical one, it can (and presumably will) change. The relationship cannot be balanced, only sublated in the Hegelian sense of the word.

In modern society there are antagonisms between competition and co-operation and exclusion and inclusion. Social relationships are predominantly coined by competition, exclusion, heteronomy and exploitation. The structures and social relationships of modern society are to a certain extent based on exclusive social relationships. Many scientists agree that this degree of heteronomy and exclusion of modern social structures is a necessary condition for the effectiveness of modern society. Some argue that the extent of co-operation is still too large and that the welfare regimes that dominated the mode of regulation of modern society after 1945 have resulted in social problems. Others argue that social problems could be contained to certain extents during the times of Fordism, but that the global problems have worsened since deregulation and privatisation have been advanced in the Western world heavily during the last 20 years. I think that the developments of Eastern and Western societies in the $20^{\text {th }}$ century have shown that both central state-based regulation and monopolising market-based regulation of society produce overall societal problems and faults. Both are indeed expressions of centralisation: state-based regulation conceives the state as the hierarchical top of society, market-based regulation conceives the economy as the hierarchical top. Both approaches have failed in advancing humane living conditions for the world population. This might be due to a lack of an overall co-operative, decentralised, pluralistic and participative character of the structures in both types of systems. Neither state-based centralisation nor market-based centralisation have fulfilled such a demand, new forms of decentralised co-operative regulation of society seem to be necessary.

Of course there is a lot of criticism of such a concept of co-operation that I am putting forward and of its consequences. Some scholars argue that competition is a necessary condition for society to exist and develop. I want to discuss the theory of competition of Friedrich August von Hayek who is one of the most important representatives of such thought in order to show the problematic implications of such assumptions.

\section{Hayek's Theory of Competition}

Friedrich August Hayek first understands co-operation in a broad sense of co-action and stresses that capitalism would be an "extended order of human cooperation" (Hayek 1988: 6) that results from unintentional, spontaneous activities that are mediated by competition and the market system. Hayek defines competition as "the action of endeavouring to gain what another endeavours to gain at the same time" (1949: 96). This implies that one achieves an advantage at the expense of others; an asymmetrical distribution of resources and power will probably be the result. Capitalism would be based on unconscious self-organization. Co-operation in the narrow sense that has to do with solidarity and altruism would be a fundamental human instinct. The communities of "primitive" people would have been based on these instincts and collectivism, Hayek says that this is why they remained very small and limited. 
The development of civilisation would depend on the emergence of rules that are passed on to following generations not by instincts, but by traditions and that would consist of prohibitions that forbade man to do what his instincts demanded. Rules of human conduct that would have enabled man to enlarge civilisation would be several property, honesty, contract, exchange, trade, competition, gain, privacy, the market system, and money. Man would have had to restrain some 'good' instincts in order to advance civilisation.

For Hayek society is guided by Smith's invisible hand that helps maintaining order although social relationships wouldn't be actively planned, but unconsciously and spontaneously organised. "We are led for example by the pricing system in market exchange - to do things by circumstances of which we are largely unaware and which produce results that we do not intend" (Hayek 1988: 14). People would blindly obey abstract rules that they don't understand and haven't made themselves, this would enable them to profit from the activities and knowledge of others they don't know and will never meet. Striving for profit of individual actors would benefit the masses.

The market and other institutions would enable the human beings to use widely dispersed information that no central planning agency could ever know, posses or control as a whole. "Information-gathering institutions such as the market enable us to use such dispersed and unserveyable knowledge to form super-individual patterns" (Hayek 1988: 15). Data would be subjective thing that are known to an individual, one person's actions would be another person's data (Hayek 1949).

Co-operation wouldn't be better than competition because the first would mean a sort of central planning that couldn't make like competition full use of the knowledge dispersed over society. "Cooperation, like solidarity, presupposes a large measure of agreement on ends as well as on methods employed in their pursuit. It makes sense in a small group whose members share particular habits, knowledge and beliefs about possibilities. It makes hardly any sense when the problem is to adapt to unknown circumstances; yet it is this adaptation to the unknown on which the coordination of efforts in the extended order rests. Competition is a procedure of discovery, a procedure involved in all evolution, that led man unwittingly to respond to novel situations; and through further competitions, not through agreement, we gradually increase our efficiency" (Hayek 1988: 19).

Profitability would be a sort of signal that guides selection towards what makes man more fruitful (ibid.: 46), market information would enable individuals to act egoistically in order to achieve profit, this would strengthen the public good. The market would transmit information about material objects (ibid.: 94), "enabling men to use, and put to work, much more information and skill than they would have access to individually" (ibid.: 97). It would transmit knowledge about prices, "of the basic fact of how the different commodities can be obtained and used" and about "alternative possibilities of action" (Hayek 1949: 51). There would be a division of knowledge: "knowledge of the circumstances of which we must make use never exists in concentrated or integrated form but solely as the dispersed bits of incomplete and frequently contradictory knowledge which all the separate individuals possess" (ibid.: 77). The anonymous, unconscious, spontaneous market-mediated combination of fragments of knowledge would bring about a distribution of resources which could be understood as if it were made according to a single plan, although nobody planned it (ibid.: 54).

Prices would co-ordinate the separate actions of different people, the price system would be a "mechanism for communicating information, [...] a kind of machinery for registering change, or a system of telecommunications which enables individual producers to watch merely the movement of a few pointers [...] in order to adjust their activities to changes of which they may never know more than is reflected in the price movement" (Hayek 1949: 86f).

Order would mean a classification of and relation between elements. Hayek distinguishes two types of orders: spontaneous, self-forming orders which he calls kosmos, and deliberately arranged and planned orders which he calls taxis. All cultural (and natural) evolution would be a process of continuous adaptation to unforeseeable events and contingent circumstances. Social development would due to the complexity of social relationships be something that is largely determined by chance, it would be "unavoidably unpredictable" (Hayek 1988: 25). Cultural evolution would depend on variation, adaptation and competition. "Not only does all evolution rest on competition; continuing competition is necessary to 
preserve existing achievements" (ibid.: 26). Historically those tribes who would have introduced trade and competition as an evolutionary variation would have had advantages over others, the latter would have adapted to these developments in order to survive. Other such evolutionary advantages would have been trade, private property, and money, they would have been necessary conditions for progress. The enlargement of society would have resulted from the invention and extension of trade and markets.

The spontaneous evolution of rules of conduct would assist the formation of self-organizing macro structures. Hayek emphasises a spontaneous nature of society. In the marketplace there would be permanent unintended consequences of actions, the distribution of resources would be affected by the impersonal process in which individuals who act for their own ends would not and could not know what the results of their interactions would be. The extended order couldn't be designed because complexity and knowledge would be created permanently by people making many decisions independently from each other according to their own purposes. The market would spontaneously and undesignedly co-ordinate the activities in such a way that order is created. Some actors would gain economic and competitive advantages, but these advantages would be communicated to others over the market, this would allow them to adapt to these changes. This would advance evolution. Evolution would happen spontaneously, not in a humanly guided way. Evolution would be a "self-ordering process of adaptation to the unknown" (Hayek 1988: 76).

The totality of events to which the market order constantly adapts would be unknown to anybody. "The information that individuals or organisations can use to adapt to the unknown is necessarily partial, and is conveyed by signals (e.g., prices) through long chains of individuals, each person passing on in modified form a combination of streams of abstract market signals. Nonetheless, the whole structure of activities tends to adapt, through these partial and fragmentary signals, to conditions foreseen by and known to no individual. [...] The market is the only known method of providing information enabling individuals to judge comparative advantages of different uses or resources of which they have immediate knowledge and through whose use, whether they so intend or not, they serve the needs of distant unknown individuals" (Hayek 1988: 76f). In the extended order, most ends of actions wouldn't be conscious or deliberate. Anonymous competitive market activities would result in "synergetic collaboration" (80) that makes use of dispersed knowledge in order to generate order and enhance productivity. "The efforts of millions of individuals in different situations, with different possessions and desires, having access to different information about means, knowing little or nothing about one another's particular needs, and aiming at different scales of ends, are coordinated by means of exchange systems. As individuals reciprocally align with one another, an undersigned system of higher order of complexity comes into being, and a continuous flow of goods and services is created that, for a remarkably high number of the participating individuals, fulfils their guiding expectations and values" (Hayek 1988: 95). Activities of single individuals would benefit other individuals whom they don't know and will never meet. "When the market tells an individual entrepreneur that more profit is to be gained in a particular way, he can both serve his own advantage and also make a larger contribution to the aggregate" (ibid.: 99).

The fatal conceit and a distinguishing characteristic of all socialist thought would be the idea that the ability to acquire skills would stem from reason. In reality, it would be the other way round, reason would be the result of a cultural evolutionary selection process in society. Man could neither create nor design the extended order by reason. The fatal conceit would be the assumption "that man is able to shape the world around him according to his wishes" (Hayek 1988: 27). Without capitalism and competition, large parts of mankind would be doomed to poverty and death. The advancement of cultural evolution would have again and again been halted by intervening governments that would have disturbed spontaneous and voluntary actions. Government would only be necessary for providing abstract rules that secure private property, i.e. the invasion of the individual's "free sphere" (63).

Decentralised mechanisms like markets would allow the fullest exploitation of dispersed knowledge, central planning or active design would imply a central actor overseeing all social knowledge. But such perfect knowledge would be impossible, hence socialism would have to fail and capitalism would 
be superior. Concern for profit would make possible a more effective use of resources. Decentralised control over resources, control through private property, would lead to the generation and use of more information than is possible under central direction (86). Co-operation, solidarity and altruism would be impossible in an extended order because there would be a high complexity of dispersed, uncontrollable knowledge and social relationships. Human beings could best achieve their ends by "relying on the selfordering forces of nature", hence they should keep from deliberately trying to arrange elements. "For in fact we are able to bring about an ordering of the unknown only by causing it to order itself" (83). "Most defects and inefficiencies" of spontaneous orders would result from "attempting to interfere with or to prevent their mechanisms from operating, or to improve the details of their results" (84). Socialism would be a threat to the welfare of the human race. The socialist effort of designing social relationships would be a longing for the life of the "noble savage" that is led by instincts and would mean a return to a "primitive" society.

Hayek's theory has been a highly influential one that has had tremendous consequences for contemporary policy design. However, his theory is based on methodological individualism and a misconception of social relationships that result in highly problematic consequences. It is wrong to assume that order can best be achieved by fully unconscious, spontaneous, chance effects of individual actions and that hence conscious co-ordination of social activities is unimportant. Hayek does not take into account that the human being is a knowledgeable, conscious, social being that has to enter social relationships and must try to consciously change nature and culture together with others according to their common wishes in order to survive (cf. Fuchs 2002c, d, e, i; Fuchs/Schlemm 2002). Without successful attempts of conscious co-ordination, society wouldn't be possible. Without social mediation, individual existence wouldn't be possible. Hayek overemphasises individual being and neglects the social character and shaping of all individual thinking and actions. Conscious, goal-directed production is a necessary condition for individual and social being, the human being must consciously identify goals that he wants to achieve and produce means in order to achieve these goals. This is both a conscious and social process. Human existence is purposeful existence, the conscious and purposeful production of a natural and social environment delimits the human world from the animal world (Fuchs/Schlemm 2002). The specific characteristic of life maintenance in society is the conscious, precautious disposal over common conditions of life by collective labour and production.

Methodological individualism reduces society to individual being-in-itself or abstract, pure-being and doesn't take into account that society means also being-for-another/ determinate-being, as well as the unity of both aspects as being-in-and-for-itself. Methodological individualism doesn't see the necessarily societal and material interdependence of individuals and doesn't grasp their process of development because it limits itself to advise them that they should proceed from themselves, it doesn't adequately reflect the real conflicts in the world, and it reduces sociality to individuality. "The methodological individualists are wrong in so far as they claim that social categories can be reduced to descriptions in terms of individual predicates" (Giddens 1984: 220). Pierre Bourdieu stresses in opposition to individualism that social order is not a simple mechanical addition of individual orders (Bourdieu 1990b: 139; 1986a: 483). Society can only be adequately explained as a dialectic of social structures and human actors, methodological individualism solves the fundamental problem of sociology of how structures and actors are related in a reductionistic manner. Hayek reduces inherently social activities like the production of wealth to egoistic, unconscious individual activities.

It is strange to argue like Hayek does that sociology is a "socialist science" (Hayek 1988: 51), and that it would be based on the assumption that the future can be forecast and shaped by human beings. Modern language would be poisoned with socialist terms like "society" and "social", Hayek (1988: 106ff) says that such terms shouldn't be used. The term society would suggest that all human systems are of the same kind and that such an order presupposes conscious collaboration. and deliberate human creation. Hayek fundamentally misconceives society in individualistic terms, he projects this error into an ideological view of science and sociology.

Hayek characterises "true individualism" by several premises (Hayek 1949: 1-32): 
- Social phenomena are based on individual action

- Many of the institutions on which human achievements rest are functioning without a designing and directing mind

- The spontaneous collaboration of free men often creates things which are greater than their individual minds can ever fully comprehend

- Individuals create things that are greater than they know, most human affairs are unforeseen results of individual actions

- Human beings are irrational and fallible beings

For Hayek the emergence of effective social orders is fully based on individual action and its unintended consequences. In reality, emergent social effects, i.e. qualities of the social whole that can't be found on the individual level, are not due to individual actions that are co-ordinated by some abstract rules and produce fully accidental results. The emergence of social wholes is due to intended and unintended creative synergies of social relationships that knowledgeable human actors and groups enter deliberately in order to achieve certain goals. Hayek's mechanism of co-ordination that produces supraindividual results is one that neglects the importance of creative, intended social relationships and reduces social wholes to individual actions.

Hayek's reductionistic misconception of society results in the assumption that all conscious action is harmful and that hence the human being should not intervene into social structures. This hypothesis doesn't see that all social development depends on permanent creative human agency and that the selforganization of society is not something that happens simply blindly and unconsciously, but depends on conscious, knowledgeable agents and creative social relationships that result in actions that have both planned and unintended consequences. Human beings try to act purposeful, society is only possible by ontological security that is based on the routinization of actions and is made to happen by the actors' reflexive monitoring their actions. The routinization of actions is a necessary condition for the reproduction and persistence of institutions and social systems. Human beings are frequently successful in achieving their consciously anticipated and defined aims, without such success society wouldn't be possible. Social actions have both intended and unintended consequences. Society is a complex system that can't be fully planned, its development can't be fully forecasted. But this doesn't mean that human beings can't act in certain ways in order to increase the possibility that certain developments will be realised and others won't be realised. Human beings can't steer the development of society, but they can design the context of complex social systems. Actors indeed can't fully plan the consequences of their actions, but it is also not the case that they can not at all successfully plan certain actions and aspects of social life and hence shouldn't try to do it. Society is only possible as interplay of chance and necessity, unintended and intended consequences of actions, spontaneous and routinized agency.

Hayek's assumptions have been empirically falsified. State policies in the industrialized countries have during the last 20 years been increasingly based on a reduction of social intervention into the economy, Hayek's assumption that the economy is capable of ordering itself spontaneously without regulation has been put to test. The result has not been as predicted by Hayek and other representatives of the invisible hand-theorem the increase of general wealth, but the increasing rise of poverty, unemployment, wage inequality, asymmetrical distribution of income and wealth, and a massive increase of insecure and precarious living conditions.

Hayek's theory is ideologically influenced, he tries to scientifically legitimate a rigid capitalistic order and a large-scale dominance of economic logic. The practical realisation of Hayek's theory of spontaneous order formation can be characterised as neoliberal ideology. Neoliberal politics aim at creating a framework for the economy that makes it possible to raise profits by minimising the costs of investment, reducing social security, and preaching self-help and self-responsibility of the individual for his/her problems and of the capability of the market to regulate itself without human intervention. This results in de-regulation, precarious job relationships, the dismantling of the welfare state, deterioration of labour and 
social policies, lowering of taxes on capital, flexible labour times, privatisation of formerly public services and industries, liberalisation of international trade policies, rise of new free trade associations (EU, NAFTA, APEC, AFTA, MERCOSUR etc.). Neoliberalism is a kind of regulation that involves the deregulation of the institutional arrangements of capital accumulation, nation-states of competition, withdrawal of the state from all areas of social life, the destruction of the welfare state and of collective responsibility, the preaching of self-help, self-responsibility of the individual for his/her problems and of the capability of the market to regulate itself without human intervention; the presentation of growth, productivity and competition as the only goals of human actions and of old ultraliberal ideas as modern and progressive, the homogenisation of the money and finance markets under the dominance of a few nations, a kind of new Social Darwinism that puts across the message that only the strong and remarkable survive in society and on the market; the establishment and institutionalisation of a permanent insecurity of wage and living conditions ("flexploitation") and of an individualisation of work contracts; state-assistance and -subsidies for large corporations. Neoliberal ideologies claim that the economy is independent from society, that the market is the best means of organising production and distribution efficiently and equitably and that globalisation requires the minimisation of state spending especially for social security; these developments are presented as something inescapable, self-evident and without alternatives. Neoliberalism as the globally dominating type of regulation results in precarious living- and working-conditions of a large, steadily increasing part of the world population. Neoliberalism has resulted in a strict dominance of the economic system in society, economic logic permeates all social realms. This is an aspect of centralisation and shows that "spontaneous market-based order formation" does indeed result otherwise than assumed by Hayek in centralisation and the fact that the structural coupling between the economy and other subsystems of society is becoming more rigid in the direction where the economy influences these subsystems (Fuchs 2003a).

Hayek conceives the economy as a fully autonomous system that is capable of steering and organising itself. The goal of politics in a society of free individuals could only be an abstract order. Hayeks main thesis is that spontaneous orders can't be steered and that outside intervention is harmful. His theory shows that based on self-organization theory one can argue that all subsystems of society are operationally closed and autonomous and that hence state intervention is harmful. The subsystems of modern society are not closed systems that can realise their self-organization independently and autonomous from the human being and other subsystems. The economy is not fully autonomous because it is based on antagonisms that produce crises and 'market failures' (cf. Fuchs 2002f, j). The economy and politics are mutually dependent, each can realise its self-organization only with the help of the other (Fuchs 2003a). The state depends on taxes that it derives from the production process and is related to economic conflicts and struggles, the economy depends on regulatory frameworks that the state guarantees with its monopoly of violence (ibid.). It is simply wrong to claim as Hayek and others do that the economy can and should be an autonomous system and that state intervention caused the crisis of modern society. Such arguments are unrealistic constructions that serve certain ideological purposes, the modern economy has never and will never be autonomous from the nation state. If either the nation state or the system of capital accumulation would break down or loose its fundamental functions this would also mean the collapse of the other system.

The assumption that the human being shall not politically intervene into the capitalistic economy implies that the possibilities of participation shall be minimised and that economic interests shall become alldetermining. It is not feasible that a system like society works the best way when responsible, decisionoriented political action is missing. Such theses overlook that the human being is an active being that possesses the ability to change the reality in well-rounded and responsible manners and in such a way that all can benefit. The global problems of society are not due to the fact that there is not enough "free market", they are due to the antagonistic and conflicting character of modern society (cf. Fuchs 2002f, j, 2003a; Fuchs/Schlemm 2003). The capitalist economy is a crisis-ridden, antagonistic system that in its development produces "market failures". The state as a regulatory instance tries to compensate for these failures in many respect, hence conscious state intervention is a necessary condition for the existence of 
capitalism. All societies are in need of mechanisms that enable the cohesion of social relationships. A mode of regulation describes the institutional framework of the important social processes (Fuchs 2002f, j, 2003a). These institutions have public, semi-public and private character and are oriented on decisionbased actions. Decisions are necessary elements of the development of all social systems, hence politics is an aspect of all social systems and societies. The self-organization of a system such as the economy is in need of political regulation. Without political regulation, i.e. decision-oriented human action, there can be no society and no economy. Hence it is wrong to argue that economic systems can or should be selfsustained and that political intervention is harmful.

Without political regulation, i.e. purposeful, institutionalised human agency, there would be no social order at all, regulation is a necessary condition for the existence and self-organization of all social systems. It is a false illusion that modern society functions better by minimising regulation. Neoliberalism has individualised regulation, but state activities are still decisive in guaranteeing capital accumulation, postfordist capital accumulation is based on a great deal of state intervention in the areas of subsidising economic corporations, and increasing the degrees of self-observation, self-description and selfcontainment of society (Fuchs 2003a).

Hayek naturalises and fetishizes competition, markets, private property and money. There is no proof for the assumption that the advancement of civilisation wouldn't be possible without these phenomena. The market surely stores information about society and hence reduces the complexity of social relationships. But the market is not the only social information storage mechanism, all social structures mediate social relationships and allow the time-space distanciation of social relationships. Social structures are medium and outcome of the globalisation of social relationships and the dialectic of disembedding and reembedding. All natural, technological, economical, political and cultural structures (natural resources, tools, property, decision power, norms, values, traditions) contain knowledge about society and help organising and simplifying the relationships of human beings (Fuchs 2002c, d, k; Fuchs/Hofkirchner/Klauninger 2001). Competitive, market-based structures have historically been an important medium of organisation and information storage, but co-operative structures have been equally important. That we are living in a society that is based on competition and private property doesn't prove that these phenomena are superior means of organisation.

Hayek is right in stressing that one important feature of the failures of "actually existing socialism" was that a central planning agency couldn't manage the complexity of society. Decentralised forms of selforganization and knowledge management seem indeed to be appropriate for establishing a socially and ecologically sustainable human order. But it is wrong to assume that co-operation means centralisation and that competition means decentralisation. Centralisation can be defined in systemic terms as the control of resources and power by one or several specific subsystems of society. This implies an asymmetric distribution of resources and power, advantages of the centralising subsystem at the expense of other subsystems. The countries of the Soviet Union were based on state-led centralisation of society, the human beings were not able to immediately control their means of life assurance in a decentralised way. This doesn't imply that capitalism is a decentralised form of organisation and that competition is an organisation principle superior to co-operation. One can in fact learn from the failures of "actually existing socialism" that a just, fair and humane society must have a fully participative, decentralised and cooperative character. Capitalism is an inherently centralistic type of ordering human relationships. Private property, capital accumulation and competitive markets result in a division into social classes where certain individuals control an increasing part of resources and power, whereas others are excluded from participation. Capitalism is based on the asymmetric distribution of power and resources, it is a centralistic order where one class centrally controls the strategic economic resources and means of production. The concepts of competition and private property are not an expression of decentralisation, but of the immanent centralistic tendency of modern society. Competition does not mean as Hayek claims "decentralized planning by many separate persons" (Hayek 1949: 79), but asymmetric opportunities that favour certain interests and groups at the expense of others. The existence of economic classes is an 
expression of the centralistic character of modern society, monopolisation as an economic phenomenon is an immanent feature of the logic of capital accumulation and market-based circulation.

It is a myth that competition, money, prices, and the market enable a good management of dispersed knowledge. Knowledge management that is based on capitalistic production and circulation is indeed very imperfect due to the fact that it is based on various antagonisms that make it hard to organise knowledge efficiently and that result in phases of economic and social crisis. These antagonisms are based on a fundamental antagonism between structures and actors in modern society. They include: antagonistic class relationships, an antagonism between the accumulation of wealth and relative pauperisation, an antagonism between necessary and surplus labour, an antagonism between use value and exchange value, an antagonism between productive forces and relationships of production, an antagonism between living and dead, objectified labour, an antagonism between single production and social need, an antagonism between production and consumption, an antagonism between socialised production and capitalistic, private appropriation, an antagonism between producers and means of production (Fuchs $2002 \mathrm{f}, \mathrm{j}$ ). An antagonistic, crisis-ridden system that permanently endangers living conditions can't be said to perfectly co-ordinate knowledge. This might in fact be due to a lack of decentralisation and co-operation.

For Hayek co-operation and solidarity are an expression of a "primitive order", complex social relationships would always be based on markets and competition. But the history of society is in fact a history of increased co-operation accompanied by an increase of competition. Modern society wouldn't exist without the historically increasing social character of production, the increasing division of labour has led from simple, individual production where one producer produces one good all by himself to complex, co-operative forms of production where one good is produced within complex social relationships that are highly spatially and temporally dispersed. The accumulation regime of Post-fordist capitalism is based on a highly co-operative character of production, the most successful corporations are frequently those engaging in participative management, corporate networks of co-operation, decentralised methods of production, and computer-supported co-operative work. Production is increasingly based on communicative and co-operative labour and interaction. The highly co-operative character of the productive forces seems to falsify Hayek's assumption that co-operation is only part of an instinctive, primitive order. Co-operation is a mechanism for effectively making use of dispersed knowledge, no invisible hand is needed here, only synergies that result from co-operative social relationships and the enhancement of these relations by modern technologies. The fact that we are today witnessing a permanent aggravation of the global social problems is due to the fact that there is an antagonism between co-operation and competition that hinders social progress and the development of society. Co-operation is increased within an overall competitive social order, the increasingly co-operative character of the social forces collides with the individualisation and tightening competitive character of social relationships. The social forces seem to put forward a new principle of decentralised, participative co-operation, within the existing social order the advantages of this principle don't seem to be achievable, co-operative and competitive aspects of social existence collide and produce social problems.

A full development of co-operation and decentralisation has neither been achieved by "actually existing socialism", nor by capitalism. Both have been based on the logic of accumulation and centralisation. The fatal conceit of "socialism" as well as of capitalism has been the lack of participation, co-operation and decentralisation. A humane order social order must be based on a participative, co-operative and decentralised management of social structures, a free association of producers can't mean the centralised control of resources, but only the decentralised management, co-ordination and control of production. Cooperation is the most effective means of managing dispersed knowledge because it favours large synergies between human actors that are due to different knowledge and capabilities that can be actively combined in such a way that emergent qualities result from the creative and productive combination knowledge. Emergence requires active social relationships, anonymous market structures and competition don't put forward synergetical advantages, the indivisible hand is an unfounded misconception detached from social reality. 
In many areas of science we can today find a number of concepts in science that point out an increased interest for co-operation. The next section will point out some aspects and implications of this shift for ecology, technology, the economy, politics, and culture.

\section{From Competition and Heteronomy to Co-operation and Self-Determination}

There is evidence (such as in the form of the new social protest movements) that people are willing to try to solve the global problems by designing society in a more co-operative and inclusive manner. In systems theory terms employed for describing the necessity of change for the better and self-determining social systems are e.g. purposeful systems, gylany, and high synergy.

Within systems science (just like in other areas of research like feminism, post-colonial studies, gender and queer studies, Marxism, critical theory, postmodern theory, cultural studies, environmental studies etc.) many scientists have ethical visions of a better society that is based on co-operation and selfdetermination. Erich Jantsch (1975) and Bela Banathy (1996) distinguish four types of self-organizing social systems: deterministic, purposive, heuristic and purposeful ones. These types vary according to the rigidity or openness of their subsystems and transformer systems. Operational targets, strategic goals and policy objectives are important in such systems. In deterministic systems, all of these categories are prescribed and remain fixed, a purposive systems formulates and selects a target, the goal is kept fixed. A heuristic systems formulates goals and targets, but still has fixed policy objectives. Purposeful systems formulate and select all of the three categories themselves. Purposeful systems are fully developed recreative systems. Our social systems today don't operate as purposeful systems, they are still trapped in determinism, purposiveness and heurism although there are material conditions as a foundation of purposeful design that is based on self-determination.

Riane Eisler and Allan Combs (1992) argue that the dominator myth is an ideology that makes people believe that it is natural and inevitable that violent aggression, armed conquest, and rule by domination govern social interactions. But historical and archaeological studies would show that there were successful cultures such as the Minoan one that were remarkably peaceful. Societies based on a gylanic or partnership principle would see linking as the primary principle of social organisation, life in such societies would be in many respect less brutal and more joyful than in heteronomous societies.

Ruth Benedict (1992) speaks of high synergy "where any act or skill that advantages the individual at the same time advantages the group" and of low synergy "where every act that advantages the individual is at the expense of others" (Benedict 1992: 59).

The shifts from competition to co-operation that are necessary in order to solve the global problems have to manifest on multiple levels in order to improve the situations of human beings and their environments: ecologically as sustainability, technologically as alliance technology, economically as participatory economy, politically as participatory democracy, and culturally as participatory culture. In the sciences we can already find slight traces of the need for such shifts.

\subsection{Towards a Co-operative Ecology}

The area where human system design effects physical and biological systems is ecology. In 1987 the Brundtland-Report of the World Commission on Environment and Development (1987) was published and sustainability was defined as a general goal of ecological and human development policies. Sustainability is seen as a development that is "meeting the needs of the present generation without compromising the ability of future generations to meet their needs" (World Commission on Environment and Development 1987). The scientific discourse has shown that implementing sustainable development in practice can only be achieved efficiently if the underlying socio-economic, socio-political and socio-cultural dimensions are not neglected. At a whole, the discussions about SD show a shift from the view of nature as an enemy that must be controlled to a view that considers nature as an important pre-condition of human existence that must be treated carefully. Human beings can and should treat nature in such a way that both can maintain 
and develop themselves adequately due to mutual connections. Sustainability can be achieved if socioand eco-sphere mutually sustain and enrich each other.

\subsection{Towards a Co-operative Technology}

The area where man makes use of tools in order to attain defined goals is technology. In designing technology there has been a shift from hierarchical expert design to user-centred and participative design methodologies. In the area of technology assessment the impacts of technological systems onto society are evaluated in order to implement a design that reduces possible risks. There is a shift from methods relying solely on expert knowledge (such as Delphi) towards methods that combine expert knowledge with the participation in the evaluation procedure of people who will be affected by the new technology. Such concepts and methods include consensus conferences, mediation, planning-cells and -workshops, future workshops and scenario writing (Wack 1985a, b; Van der Heijden 1996, Ludwig 1995, Jungk/Müllert 1989, Gethmann/Grundwald 1996, Bruechler/Simonis/Sundermann 1999, Albers 2001). The hierarchic and centralised design of technologies resulted in static processes that couldn't integrate the end users and caused uncontrollably high technological risks. Technology still mainly serves dominating destructive interests, it is not primarily a means of simplifying human existence, but a means of simplifying capital accumulation by increasing productivity. The primacy of productivity detaches technology from satisfying reasonable human and social needs in accordance with humanistic values. Terms such as alliance technology (Bloch 1986) or conviviality (Illich 1975) describe a qualitative different design and application of technology within a qualitatively different social framework. They describe a "friendly" relationship of human beings and technology where technology is considered a means of achieving human goals more effectively and in accordance with human values such as freedom, participation, co-operation, peace, beauty, justice and fairness.

\subsection{Towards a Co-operative Economy}

The area where man produces, distributes and consumes goods in order to satisfy his needs is the economy. New concepts and methods of management and organisation stress the delegation of decisionmaking authority, teamwork, decentralisation, flexibilization, flat hierarchies, active participation of the workforce, computer support and network structures. Hierarchic control and centralising organisation methods turned out as harming economic efficiency. Participation in decision-making is a human right and supports economic efficiency. New concepts and methods include the virtual enterprise (Davidow/Malone 1993, Martinez et al. 2001), the atomised organisation (Ryf 1993), the fractal company (Warnecke 1992), the modular factory (Wildemann 1988), the integral enterprise (Schwaninger 1989), the knowledgecreating company (Nonaka/Takeuchi 1995), the intelligent enterprise (Willke 1995), the dissipative enterprise (Jenner 1998), the learning organisation (Argyris/Schön 1999; Pedler et al. 1994), lean production (Womack et al. 1991, Warnecke/Hüser 1995), business reengineering (Hammer/Champy 1995), team syntegrity (Beer 1994, Espejo/Schwaninger 1998), systemic and evolutionary management (Laszlo/Liechtenstein 1992, Lutz 1992, Malik 2000), quality circles (Deppe 1992), change management (Capra 1992), knowledge management (Bullinger 1998), innovation management (Leder 1990), quality management (Massotte/Bataille 2000, Miller 1996, Probst 1983), innovation ecology (Lutz 1994), selforganization management (Probst 1987, Romme 1995) and innovation networks (Frenken 2000).

A participatory economy is one where resources are owned, produced and used commonly. The concept of the participatory economy could maybe provide a more sustainable way of social management. However, the different methods and concepts of organisation and management that have emerged recently don't seem to want to go beyond the overall exclusive character of modern society.

The paradigm-shift in organisation and management theory has not been an accidental one. In the early 1970s, the Fordist mode of development of capitalism entered crisis. One of the reasons was that the hierarchical Taylorist model of organising work reached its limits and promoted refusal of work and class 
struggle because the work force couldn't stand the permanent and extraordinary psychological and physical burdens. Other reasons were the technological and organisational limits the centralist Taylorist methods had reached. As a result, the growth rate of productivity decreased and wages and constant capital relatively increased. These processes together with the tendency of profit rates to fall produced falling profit rates and an overall crisis of capitalism (Fuchs 2002f). The economic diffusion of computer technology is also related to the crisis of Fordism (see Fuchs 2001a, b, 2002f). As a reaction to the relative fall of the profit rates, computerisation and automation have been put forward in order to save labour costs and to increase the rates of profit again. Informatization and computerization are medium as well as the outcome of the crisis of Fordism. The transition from Fordism to Postfordism took place in the framework of the search for a solution of the crisis of Fordism and capital accumulation. Neo-liberal politics aim at creating a framework for the economy that makes it possible to raise profits by minimising the costs of investment (constant and variable capital), reducing social security, and preaching self-help and selfresponsibility of the individual for his/her problems and of the capability of the market to regulate itself without human intervention.

This results in de-regulation, precarious job relationships, the dismantling of the welfare state, deterioration of labour and social policies, lowering of taxes on capital, flexible labour times, "housewifization," etc. Other characteristics of the Postfordist mode of capitalist development are a new phase of economic globalisation (see Fuchs/Hofkirchner 2001, 2002a, b), the creation of national states of competition, the outsourcing, decentralisation and "flexibilization" of production, lean management, just-intime production, the flattening of internal hierarchies in corporations, small organisational units in corporations, delegation of decision-making from upper hierarchical levels to lower ones, decentralisation of organisational structures, team work, semi-autonomous working groups, tertiarization and informatization of the economy, triadization of international trade and of capital-export, and diversified quality production. The use of modern information and communication technologies (ICT) in organisations is due to economic interests. Without the global crisis of Fordism, the new technological paradigm would have emerged sooner or later, but this process would have taken place much more slowly. The massive diffusion of ICT results from capitalism's permanent search for effective means of production, rationalisation and mechanisation. ICT make outsourcing and de-centralisation of production, teamwork, the "flexibilization" of jobs and the flattening of organisational hierarchies much easier. These new technologies are a logical result of the development of the productive forces.

Today, we live in a Postfordist, neo-liberal, information-societal type of capitalism (see Fuchs 2001a, b, 2002f). A new mode of development has emerged which has new emergent qualities. It involves a Postfordist regime of accumulation, a neo-liberal mode of development and a disciplinary regime that has been described by the term "society of control." The disciplinary regime that dominated during the area of Fordism operated with the help of disciplines and disciplinary milieus. Disciplines are methods that secure the submission to external forces by surveillance and punishment (Foucault 1976). They are inherent in modern institutions such as schools, prisons, families, universities, hospitals, corporations, etc. because these milieus try to enclose the individual. Disciplines were also incorporated into the Fordist apparatuses of mass production, especially into assembly lines. These aspects still exist today to a certain extent, but concerning the disciplinary regime there is also a shift from the "disciplinary society" (Foucault) to what Gilles Deleuze (1993) calls the "society of controls." Controls are internalised disciplines, forms of selfdiscipline that present themselves as liberating and operate in a more subtle manner: "Enclosures are molds, distinct castings, but controls are a modulation, like a self-deforming cast that will continuously change from one moment to the other, or like a sieve whose mesh will transmute from point to point [...] The old monetary mole is the animal of the space of enclosure, but the serpent is that of the societies of control. We have passed from one animal to the other, from the mole to the serpent, in the system under which we live, but also in our manner of living and in our relations with others. The disciplinary man was a discontinuous producer of energy, but the man of control is undulatory, in orbit, in a continuous network. [...] The coils of a serpent are even more complex than the burrows of a molehill" (Deleuze 1992). 
The mole as a symbol of disciplinary society is faceless and dumb and monotonously digs his burrows; the snake is flexible and pluralistic. The individual in Fordist capitalism was expected to carry out monotonous labour; management expects individuals in post-Fordist capitalism to be flexible, innovative, motivated, dynamic, modern, young, and agile, and it wants them to identify with the corporation and to have fun at work. Strategies of participative management aim at the ideological integration of labourers into corporations. This is a new quality of the disciplinary regime that aims at a rise of profits by an increase in productivity and cost reductions achieved by the workers' disciplining themselves. Bonus systems, team work, share options, corporate identity, attractive design of the work place, construction of a community between management and workers ("we"-identity), advancement of spirit of enterprise within the workforce etc. are part of this strategy that constitutes new qualities of the disciplinary regime.

So what I am arguing is that the shift from hierarchical expert management towards participatory management reflects an ideological shift in modern society which no longer involves a dominance of hierarchical control, but a strategy of integration that is expected to result in a rise of profits. Participation in social systems (not only in socio-technical systems) understood as the individual and collective right and responsibility to design those systems in which people live all by themselves can be justified in two ways: either by arguing that there is a political right to self-determination, democratic involvement, and participation, or by arguing in an instrumental sense that in order to achieve good results, participation is necessary. In informational capitalism, "participation" is participation in the second, rather instrumental sense, which serves economic interests. If one takes a look at the precarious living and working conditions that the majority of the population of the world society has to endure today, it becomes clear that this type of participatory management does not at all result in a humanisation of work and life.

In organisation and management theory, "participation" is understood in a rather narrow sense of the term that excludes overall societal and political issues. Full participation would have to include an inclusive control and ownership of products and the means of production and on the political level overall direct democracy in the sense of people affected by determining decisions collectively and by themselves (see Fuchs 2001b). "Participatory" management is a method of rationalising and optimising the production process in such a way that profit can be achieved effectively. The division of labour inherent in capitalism that requires a class relationship between those owning the means of production and the results of the production process and those depending on the entrance into labour relationships is maintained in informational capitalism. Despite all the changes we are witnessing today, this antagonism remains an unchanged central characteristic of society. "There is still a division between those who own the valuable resources on which the information economy is dependent and those who merely own their ability to labour in such an economy. [...] In the information economy even if knowledge creators are themselves individuals, the ownership of the bulk of valuable knowledge resources remains with capital" (May 2000). "Participatory" methods of management and design help to ideologically forestall social change towards a fully participatory society.

Khandwall (1977) characterises elements of participative organisations: superiors have trust and confidence in subordinates, subordinates feel free to discuss any job-related matters with their bosses, reward systems, participatory set goals, improvement programs, evaluation of progress; great deal of upward, downward, and horizontal communication; extensive, friendly interaction between superior and subordinates, great deal of co-operative teamwork, decision-making is done throughout the organisation and is integrated through interlinked groups, awareness of organisational problems throughout the organisation, subordinates are fully involved in decisions related to their work, consensus-oriented team decision-making at the level of top management, decision making is designed to motivate the implementation of decisions, team goals are established by group discussions, participation in control functions, use of human relations in effecting organisational changes and securing better co-operation from employees, use of techniques such as sensitivity training and managerial grid for organisation development. This is a narrow understanding of economic participation that serves economic interests, a participatory and co-operative ownership of the means of production and the products is avoided as a characteristic here. True economic participation would imply a stronger socialised character of ownership. 
Khandwall suggests that "another aspect of the participative mode's ideology is the notion that cooperation is better than competition, and warm, friendly relations among organizational members are more desirable than mutual hostility and suspicion. This is best achieved by power equalization, in sharp contrast to the power struggles characteristic of the coercive mode" (Khandwall 1977: 418). Co-operation indeed is better than competition in order to achieve economic democracy, but this requires full economic co-operation, not a selective and opportunistic type of co-operation that bases only those aspects of an organisation and of society on co-operation that help ideological integration and don't conflict with profitoriented production.

Organisation and management theory suggest co-operation both as intra- and inter-organisational design principle. On the inter-organisational level co-operation between firms (business networks) is suggested in order to reduce transaction costs and increase profit. "The implications for management ... is that, if a business network is very weakly connected, it is not very complex and will only be able to survive in less complex environments. On the other hand, networks that are too richly connected are in danger of producing very complex, chaotic patterns of behavior that adversely effect the capacity of the network to evolve effectively and retain beneficial innovations in any part of the network. Too many parts of the network are affected by any change, resulting in many conflicts of interest, resistance and reduced performance. Somewhere in between, the degree of interconnection results in a network with a superior capacity to evolve and respond to complex environments...Entities incorporating cooperative strategies, i.e., those including some concern for other parties' outcomes in interactions, are more likely to be long-run system survivors, i.e., to be among the winners who continue to operate within the system. And systems made up of cooperators mutually produce more richly structured and stable networks" (Wilkinson/Young 2002: 128). Again this is a narrow understanding of co-operation that promotes co-operation in order to achieve advantages in the competitive struggle for profits.

The development of the productive forces has reached a level where the high productivity standards would enable a true participatory economy where there is wealth for all without hard work as well as a maximum of free time and the abolition of alienated, estranged labour. The productive forces are still trapped within modern social relationships, this antagonistic relation of forces and relations today produces social problems such as technological unemployment and poverty. Establishing an economic democracy of ownership, production, distribution and allocation is a way of achieving humanistic goals.

Michael Hardt and Toni Negri $(1994,2000)$ argue that in order to remain productive and profitable, capitalism has transformed itself into a global network structure that they call "empire". Production in the empire would be based on intellectual, immaterial and communicative labour. The three aspects of immaterial labour would be communication, interactivity in using symbols/solving problems and manipulation of affects. Immaterial labour produces services, cultural products, knowledge or communication. Transnational corporations produce communicative networks and a new type of sovereignty that weakens the power of the nation state. The diffusion of computer-, information- and communication technologies is part of the social restructurations that have resulted in the empire. The process of industrial modernisation would have reached its limits, hence postmodern capitalistic production based on informatization and the rise of service industries would have emerged during the last decades. Computer technology would homogenise the labour processes in the sense that it becomes the universal tool of production. Affective labour would be another aspect of immaterial labour besides computerised labour. Negri and Hardt say that all three aspects of immaterial labour (communication, symbolic analysis, affective labour) are immanently co-operative. Productivity, wealth and creation would today have the form of co-operative interaction that makes use of linguistic, communicative and affective networks. Labour in the information sector would be what they call abstract co-operation: Production is co-ordinated by information-technologies and hence the workers don't have to be co-present at one place.

The analysis of Negri and Hardt is important because it once again shows that the development of the productive forces has reached a stage where capitalism is based on co-operative economic, political and cultural networks. It enables high degrees of productivity and socialisation which are both material 
preconditions of a fully participatory, democratic and co-operative society where socialisation permeates all areas of public life including ownership of the means of production that are today still treated as private property although with the increased importance of information as a social, collective and historical product the concept of private ownership no longer seems to make sense. We today find the objective, material conditions for a free society, but at the same time the culminating antagonisms produce global problems and false consciousness. The new technologies are also used in such a way that the forestalment of social change by control and manipulation is achieved. Negri and Hardt are too optimistic concerning already achieved progress, it sometimes seems like they consider the new emerging immaterial workers as automatically emancipatory. They speak of "revolutionary subjectivity", "social workers" and the "multitude" in order to characterise emancipatory subjectivity of co-operating individuals. However, technologies that are based on and foster co-operation don't automatically mean that their users have liberating consciousness that questions capitalism. The newly emerging progressive social movements can be considered as a type of liberating subjectivity, but the immaterial workers in software companies, the ITbranch and the New Economy hardly can be considered as emancipatory subjects. Well-qualified employees tend to reproduce the existing ideologies of competition, achievement, career and productivity. One has e.g., hardly heard about strikes or unionising in the New Economy. Negri and Hardt overlook that participatory and co-operative management is an ideology that successfully integrates workers and forestalls liberating subjectivity. An objective potential for progression exists today due to the high degree of productivity and networking of the economical and technological productive forces, but this potential still has to be realised by human subjects in order to achieve real human progress.

Human labour finds itself within conditions that can indeed be described as prerequisites of a fully cooperative society. But it is not determined whether revolutionary subjectivity can arise and organise itself to such an extent that the material conditions can gain subjective and objective truth. This depends on the outcome of existing struggles, at this moment of time it doesn't at all look like enough subjective power can be mobilised, rather manipulation and control flourish and produce false consciousness globally en masse. Participatory management has an ideological character, it hinders emancipatory subjectivity. The material foundations for a society in which individuals co-operate with a high degree of solidarity and where they have a new degree of self-realisation and well-rounded development exist. But, and these are my greatest concerns, it is still the case that change of the existing direction of progress would mean fundamental change, but social change presupposes that there are vital needs for it as well as the experience of intolerable relationships. In the society we live in, these needs and experiences are forestalled by an apparatus of manipulation. The establishment of a sustainable and socially self-organized society needs self-organizing subjects who develop critical consciousness and make use of it in social struggles. It is not certain whether or not this consciousness can be developed and what outcome struggles that result from it will have. The productive forces that are entangled into the existing antagonisms are ready for a higher type of existence. The outcome depends on the conditions of social struggles and of consciousness that develops itself in these struggles. This would also have to encompass subjects who have understood the reasons for their slavery, want liberation and have realized ways towards it (Fuchs 2002g). The new social movements are a type of slight revolt, if self-organized, decentralised forms of protest spread out, one will have all reason to assume that there can be change for the better.

In society, information can only be produced jointly, not individually. Whenever new information emerges, it incorporates the whole societal history of information, i.e. information has a historical character. Hence it seems to be self-evident that information should be a public good, freely available for all. But in informational capitalism, information has become an important productive force that favours new forms of capital accumulation. Information is today not treated as a public good, rather as a commodity. There is an antagonism between information as a public good and as a commodity. This antagonism stems from the fundamental capitalistic antagonism between products as use values and as exchanges values. Exchange value dominates use value, not the usefulness of a product is its main aspect, but its commodification and valorisation. 
Information has specific characteristics that on the one hand are very advantageous for capital accumulation (Fuchs 2002h), but on the other hand pose problems for and set limits to the commodification of information (Fuchs/Hofkirchner 2003):

- Information is a non-substantial (nichtstofflich) good that is generally not used up by its manifold usage.

- Information expands during its usage.

- Information can be compressed.

- Information can replace other economic resources.

- In fast networks information can be transported at the speed of light.

- Purchasers of information only buy copies of the original data.

- The costs of reproducing information are generally very low and will be further diminished by technological innovations and progress.

An information product has a very low value (i.e. very little time is needed for producing or copying one single product), but is sold at a much higher price. The profits in the New Economy and the IT-sector are a result of this gap between value and price of information (Fuchs 2002h). Large corporations try to monopolise the production and distribution of information. The media are dominated by large transnational corporations like AOL Time Warner, Disney, Viacom, Bertelsmann, Murdoch, AT\&T, Sony and Seagram, the largest corporations all operate in the media- or IT-sector (cf. table 2). Corporations make use of Intellectual Property Rights (IPRs) in order to extract economic profit from information.

\begin{tabular}{|c|c|c|c|c|c|c|c|}
\hline Company & Statement & Industry & $\begin{array}{l}\text { Sales } 1999 \\
\text { (Billions of } \\
\text { USD) }\end{array}$ & $\begin{array}{l}\text { Sales } \\
\text { Increase } \\
\text { from } \\
1998\end{array}$ & State & Employees & $\begin{array}{l}\text { Market } \\
\text { Capitalisation } \\
\text { in Billions of } \\
\text { USD }\end{array}$ \\
\hline $\mathrm{CISCO}$ & $\begin{array}{l}\text { "Empowering the } \\
\text { Internet } \\
\text { generation" }\end{array}$ & $\begin{array}{l}\text { Electronic Data } \\
\text { Processing } \\
\text { Equipment }\end{array}$ & 12154 & $43,7 \%$ & USA & 21000 & 451,8 \\
\hline MICROSOFT & $\begin{array}{l}\text { "Where do you } \\
\text { want to go } \\
\text { today?" }\end{array}$ & Software & 19747 & $36,3 \%$ & USA & 31396 & 410,9 \\
\hline INTEL & $\begin{array}{l}\text { "Making the } \\
\text { Internet as } \\
\text { powerful as our } \\
\text { processors" }\end{array}$ & Semiconductors & 29389 & $11,9 \%$ & USA & 64500 & 385,6 \\
\hline $\begin{array}{l}\text { AOL TIME } \\
\text { WARNER }\end{array}$ & $\begin{array}{l}\text { "AOL anytime, } \\
\text { anywhere" }\end{array}$ & $\begin{array}{l}\text { Internetservices, } \\
\text { Entertainment }\end{array}$ & 32110 & -- & USA & 79600 & 252,7 \\
\hline AT\&T & $\begin{array}{l}\text { "It's all within your } \\
\text { reach" }\end{array}$ & Telecom & 62391 & $17,2 \%$ & USA & 107800 & 223,7 \\
\hline $\begin{array}{l}\text { DEUTSCHE } \\
\text { TELEKOM }\end{array}$ & $\begin{array}{l}\text { "Innovation and } \\
\text { service on a } \\
\text { global scale" }\end{array}$ & Telecom & 35300 & $1,2 \%$ & D & 203374 & 212,2 \\
\hline NTT & & Telecom & 76378 & $-0,3 \%$ & JAP & 138150 & 204,9 \\
\hline LUCENT & $\begin{array}{l}\text { "Taking networks } \\
\text { forward“ }\end{array}$ & $\begin{array}{l}\text { Network } \\
\text { Communications }\end{array}$ & 38303 & $27,1 \%$ & USA & 153000 & 201,0 \\
\hline IBM & $\begin{array}{l}\text { "We're not } \\
\text { changing our } \\
\text { name. Just } \\
\text { everything else“ }\end{array}$ & $\begin{array}{l}\text { Software, } \\
\text { Hardware, } \\
\text { Services }\end{array}$ & 87548 & $7,2 \%$ & USA & 291067 & 186,6 \\
\hline $\mathrm{MBI}$ & "generation d" & Telecom & 37120 & $110 \%$ & USA & 77000 & 114,2 \\
\hline
\end{tabular}

Table 2: The Big Players in Informational Capitalism (Source: World-Information Exhibition, http://world-information.org)

Social movements like the Open Source community oppose the commodification of information and argue that information should be freely available to everyone. Information can be easily copied and distributed over the Internet. This makes it difficult for corporations to prevent the free sharing of 
information. The MP3-movement and software applications like Napster, KaZaA, Audiogalaxy, LimeWire, Morpheus, EDonkey, WinMX, iMesh, Bearshare, Blubster, SoulSeek, Overnet, Toadnode, Grokster, Blubster that distribute digital music files for free over the Internet pose a threat for large corporations (e.g. Virgin will close down some of its "Megastores" during the next years due to heavy losses that have been caused by the free sharing of music over the Internet). Hence the Recording Industry Association of America (RIAA) sues operators of such network-applications, but whenever one operator has been forced to quit its services, others have emerged. This shows that information and informational networks like the Internet are hard to control and that one should consider whether it is just and fair to monopolise and commodify information and to destroy its public character. All sorts of networked open source activities show the power of co-operation and the possibility of enhancing co-operation by making use of digital networks.

\subsection{Towards Co-operative Politics}

The realm of society where man makes use of power in order to reach decisions is politics. Concepts and models of participatory democracy stress the capacity of ordinary people to exercise responsible, collective, public leadership; voluntary associations and informal networks in which individuals and groups engage in activities of public consequence, people's creativity and initiative to fashion innovative solutions to community problems, the notion of citizens and representatives deliberating about public problems and solutions under conditions that are conducive to reasoned reflection and refined public judgement, a mutual willingness to understand the values, perspectives, and interests of others; the possibility of reframing interests and perspectives in light of a joint search for common interests and mutually acceptable solutions. Dominant themes are that individual rights need to be balanced with social responsibilities, that autonomous selves do not exist in isolation, but are shaped by the values and culture of communities, and that cultural factors result in distinctive political practices and institutions. Models and concepts of participative democracy emphasise social responsibility and promote policies meant to stem the erosion of communal life in an increasingly fragmented world. There is an interest for finding ways of countering the growing sense of powerlessness and alienation from the political process by reversing the shifting of power away from local communities towards centralized bureaucratic structures. A distinctive political perspective contained in these concepts is to identify valued forms of community and to devise policies designed to protect and promote them.

Models and concepts include strong democracy (Barber 1984), communitarianism (Etzioni 1993, 1995, 2001; Tams 1998), deliberative democracy (Mansbridge 1980, Mathews 1994), citizen politics (Center for Democracy and Citizenship 1995), civil society (Cohen/Arato 1992, Eberly 1994, Walzer 1992), citizen society (Beck 1999), consensus organizing (Gittell 1998, Rubin/Rubin 2001), libertarian municipialism (Bookchin 1991), and integrative democracy (Fotopoulos 1995).

A system can be considered as participatory if power in the system is distributed in such a way that all members and concerned individuals can own the system co-operatively and can produce, decide and live in the system co-operatively. Participation is more than co-operation, it is an integrated notion of cooperative economical, political, cultural, technological and ecological activities. In a participatory system learning, improving and using the system is considered as very important, the users' experiences, values, ideas, wishes and visions are integrated into the design process, users are enabled to understand the system and their role in the system, if they know what they have to learn to play their role, if the design principles aim at creating consensus among those who are effected by the system and if the design ensures that people will take part more effectively and at a deeper level of commitment in the design process and systemic evolution (Banathy 1996, Ackoff 1981). Participation is based on self-determination, direct democracy, co-operation and inclusion; it stands in opposition to heteronomy, social hierarchies, coercion, competition and exclusion. In a participatory organisation, each involved individual has the same possibilities and means of influencing the resulting structures in his own sense and purpose; the macroscopic structures are co-operative social relationships. Owning, producing, deciding, living and 
learning are co-operative and inclusive processes in participatory organisations. Today, decision-making is detached from those who are affected by decisions. "The centers of decision should not be removed from the people whose lives are affected by the decisions" (Laszlo 1992: 239). As society is becoming more global, there should also be more global types of governance that go beyond the isolationism of the nation state. Co-operative international governance could be based on the political principle of unity in plurality: decisions are reached in decentralized manner by all those who are affected by them, global communication and understanding try to integrate decisions and political values at the global level. Local decisions should be decentralised, decisions that have global scope should be internationally discussed and decided.

Participation is frequently understood in the very narrow sense of concerned people taking somehow part in decision processes. Such an understanding is limited to the political dimension and says nothing about the scope and dimension of participation. Participation is based on co-operation because it is a social activity and if people take part in social activity one expects them to produce some common, positive results. When I speak of participation I mean a high degree of participation, hence participation is directed against hierarchy, coercion, heteronomy and exclusion and must be based on self-determination, direct democracy, communication and inclusion.

There are several dimensions of participation in a social system or in society: producing, owning, consuming (economic dimension), deciding, goal-setting, evaluating (political dimension), forming knowledge/norms/values/images/visions, communicating, networking, self-realising (cultural dimension). Participation in each of these ten dimensions can be low, medium or high/full. Low participation means hierarchy and unequal distribution of power, in medium participation there is already a flatter hierarchy and a less unequal distribution of power, but hierarchy and unequally distributed power are still dominating, and in full participation there are no hierarchies and there is an equal distribution of power. E.g., in most economic organisations that exist today there is low economic participation: some own the means of production, capital and the produced goods, others don't. Full participation here would mean that all together produce and own in a collective process. The participation matrix describes the degree of participation in an organisation/society with the help of the three dimensions of economy, politics and culture and an analysis of the scope of participation (economic, political, cultural).

\begin{tabular}{|c|c|c|}
\hline \multicolumn{1}{|c|}{ ECONOMIC } & POLITICAL & CULTURAL \\
\hline LOW & LOW & LOW \\
\hline MEDIUM & MEDIUM & MEDIUM \\
\hline HIGH & HIGH & HIGH \\
\hline
\end{tabular}

Table 3: The participation matrix

The computerisation of society and the emergence of the information society has changed politics. New digital media and networks such as the Internet pose both great new possibilities and risks (Fuchs/Hofkirchner 2003). It is short-sighted to say that the new ICTs are solely dangerous or solely advantageous. It depends on how the human beings make use of and design these new media, i.e. participatory new media can only exist in a participatory, co-operative society. The new media are today mainly used in order to enhance economic and political domination, they are new means of capital accumulation, control, warfare, surveillance and destruction. Society is not yet a global village, the new media today don't put forward agoras of the global village. Society is today a global sphere of capital accumulation, not a global noosphere of solidary co-operation. The cyberspace is not a political agora, but a system of commerce and stupidifying amusement. But there is no need to be too pessimistic, because 
the technological networking of the world pits forward a new principle: all-embracing, participative, networked co-operation. The emergence of numerous non-profit organisations (NPOs) and nongovernment organisations (NGOs) are not only simply the "vicarious agents of neoliberalism", their modes of decentralised, networked self-organization show that political globalisation can be based on global cooperation and they stress dialogic communication and co-operation and hence facilitate new progressive principles. Many of the political NGOs that engage in critique in the new protest movements have an international character, international practices and address international issues. They constitute a political form of globalisation.

Based on solidary co-operation the sociosphere could develop into a noosphere, a global sphere of reason, co-operation, solidarity and responsibility (Teilhard de Chardin 1964, 1965, 1966, Vernadskij 1997). The technological and economic globalisation of the world anticipates and is a shining forth of a well-rounded solidary interrelation of individuals in an association of humanity. But I doubt that the reaching of a noosphere can be achieved if we continue the current destructive and exploitative forms of designing society. The new technologies are embedded into an antagonism between political participation and political control/surveillance, they foster both positive and negative new political possibilities. It depends on human agency and struggles which tendency will be the more successful one. I want to point out some new possibilities and risks that the new media pose for democracy. Aspects that could strengthen democracy are the following ones:

- Increase of the access to information: the Internet poses a simple and cheap means for citizens to access political information.

- Realisation of polydirectional interactions: Traditional political media such as television, radio or printed media have a one-dimensional character, they only work in one direction from the sender to the receiver without possibilities for mutual interaction. The interactivity of the Internet can extenuate this elitist character of traditional media, there is a shift from one-to-many- to many-to-many- and all-to-allcommunication.

- Production of publicity and counter-publicity: Political self-organization can be supported by making use of new media. The Internet is a medium of organisation in contexts of civil society on a local, regional, nationwide and global level.

- Enlargement of time-space-distanciation and -autonomy of social relationships: New media enable new forms of global communication that are not temporally and spatially bounded/limited.

- Immunisation of political communication against authoritarian structures: The decentralised character of the Internet makes censorship and the establishment of new autocratic, centralising, controlling structures that are based on an asymmetrical distribution of power rather hard tasks. The Internet is hard to control and can in the case of the blockage of political communication simplify the distribution and exchange of political information (see e.g. oppositional movements in Serbia).

- New possibilities of an administration for the people and for self-government: Administrative procedures can be simplified and made more transparent by using digital, networked technologies.

- Improvement of information management: Political information can be distributed much faster over the Internet and hence be accessed more quickly and more efficiently by the citizens. This also means a faster access to information for political groups.

- Optimisation of the formation of individual and public opinions: Many sources can be employed and compared in order to form ones own political views, values and opinions. The new media pose the possibility for a pluralistic political public with numerous sources of political information.

- Social and informational decontextualization: One can move anonymously in virtual political spaces, this can result in the production of new political discourse cultures.

- New patterns of perception and action: Complex political circumstances can be presented with the help of multimedia (images, text, sound, video etc.)

- New possibilities for producing and discussing political topics over the Internet 


\begin{tabular}{|l|c|c|c|}
\hline Region & $\begin{array}{l}\text { Percentage share } \\
\text { of world } \\
\text { population }\end{array}$ & $\begin{array}{l}\text { Number of } \\
\text { Internet users } \\
\text { (millions) }\end{array}$ & $\begin{array}{l}\text { Percentage share } \\
\text { of worldwide } \\
\text { Internet users }\end{array}$ \\
\hline Worldwide & $13,5 \%$ & 605,60 & \\
\hline Africa & $61,1 \%$ & 6,31 & $1,0 \%$ \\
\hline $\begin{array}{l}\text { Asia/Middle } \\
\text { East/Pacific }\end{array}$ & $11,7 \%$ & 192,36 & $31,8 \%$ \\
\hline Europe & $5,1 \%$ & 190,91 & $31,5 \%$ \\
\hline Canada/USA & $8,5 \%$ & 33,35 & $30,2 \%$ \\
\hline Latin America & & $5,5 \%$ \\
\hline
\end{tabular}

Table 4: Distribution of worldwide Internet users (Source: http://www.nua.com/surveys/how_many_online/index.html, March 2003)

These possibilities are only used to a minor extent today, large-scale political participation has not yet been established. There is no free access to cyberspace, only a small percentage of the world population has access to the new media, the cyberspace is dominated by white, male Americans and Europeans. The cyberspace and new media reproduce segmentations along the lines of class, gender, origin, age and qualification. The distribution of the worldwide Internet users shows that there are major disparities (tab. 4).

Technological artefacts reflect social relationships of domination and property. This also applies to the Internet. The access to cyberspace demands financial resources for telephone, modem, computer, Internet Service provider etc., but at the same time we are witnessing an increasing social gap. Other dangers that the usage of the new media poses for democracy include:

- The Internet is mainly a means of realising profit, it has been transformed from a military technology (ARPA-Net) to a means of restructuring and accelerating business processes, it is a location of capital accumulation and a means of advertising that encompasses interactive and multimedia dimensions. Politics is a minority field in the World Wide Web, at maximum $1-2 \%$ of all websites have political contents, the main contents on the Net are sex and commerce.

- Where the Internet is used as a means of political communication, it supports already existing relationships rather than producing new political communities.

- Computer mediated political communication is in most cases only an exchange of opinions between individuals because there is no public space for discourse with communication possibilities for attendees.

- There are restrictions in computer mediated communications: no obligations, no binding character of communication, no social cohesion, no mimic and gestures, misunderstandings can easily show up. Jürgen Habermas (1984) has shown that in order to achieve a common understanding, certain claims to validity of communication must be fulfilled:

* comprehensibility (a statement must be comprehensible for the communication partners),

* truth (statements must be according to facts),

* truthfulness (intention and statements must be in accordance with each other),

* rightness (the normative context of communication must be clarified and agreed upon).

The technological mediation of communication certainly makes such a fulfilment more difficult, but not impossible. Truthfulness and rightness are lost in computer mediated communication, this complicates co-operation in cyberspace. Computer mediated communication is much more expressive than normative.

- Underrepresentation of alternative voices: Decision and representation structures in the Internet are monopolised. The Internet Research Task Force (IRTF) is one of the highest decision-reaching institutions concerning the cyberspace, it mainly consists of representatives from US corporations and from communications industry. It is very hard to be recognised in the Internet for unknown or less wellknown political actors, movements and institutions than for established and well-known ones. Alternative voices are less heard or read on the Internet than Mainstream ones. The assignment of 
domain names (such as microsoft.com) has been commodified. Formerly the state-owned National Science Foundation was in control of this area that has now been privatised and is now in the hands of Network Solutions Incorporated (NSI), which is a multimillion dollar corporation. The top-level-domains (com, edu, gov, mil, org, net, .co.uk etc.) are administered by the Internet Assigned Number Authority (IANA). Power in the Internet is to some extent also controlled by Microsoft and Netscape because they supply people with browser software and hence can exercise technological control of standards such as HTML (hypertext mark up language, the computer language that is used in order to write a document that is published on the Internet). In the World Wide Web (the graphical interface of the Internet that one uses in order to locate and browse hypertext documents) there are links from one page to others. A link is reference that can be used in order to directly access the page that has been linked. The unequal distribution of power in the Internet is also shown by the fact that pages which have many references to itself are visited much more often than others. Again, the web sites of large economic institutions that have trademarks and brand names are linked more frequently than small distributors of alternative knowledge. It is the same with established political parties in comparison to small grass-roots movements. In order to become "visible", a web page must be indexed by search engines. People can visit these engines, type in which information should be located and as a result links to suitable web pages are listed. If your page is listed on top of the results, it is very likely that it will be visited frequently. Again this is an issue of economic power. Many search engines sell top priority listings as commodities, others index those pages on top that are linked most often by other sites. All of this results in the fact that web sites that are owned by institutions and persons that do not have a lot of political and economic power, are only given a very low priority. So if you are e.g. looking for the term "political news" with a search engine such as google.com, you will find CNN, the Washington Post, BBC etc. as top results, but you won't find indymedia.org, alternet.org, z-mag.org etc. given a top priority. You will find plenty of sex sites on the Internet, but only one or two per cent of political contents and only a minor share of these political sites will contain critical and alternative political information.

\subsection{Towards Co-operative Culture}

The area of society where norms, values and knowledge are defined and constituted within habitus and life-style is culture. Education is an important cultural area. A shift from traditional to participatory learning methods has taken place. "Cooperation is working together to accomplish shared goals and cooperative learning is the instructional use of small groups ... so that students work together to maximize their own and each other's learning. ... This, a student seeks an outcome that is beneficial to him- or herself and beneficial to all other group members. In cooperative learning situations, students perceive that they can reach their learning goals only if the other students in the learning group also do so... They become mutually responsible for each other's learning" (Johnson/Johnson 1992: 195f).

Participatory learning stresses the importance of co-operation and group work, it fosters individual accountability in a context of group interdependence, it favours a plurality of viewpoints, abilities, gender, race etc. as well as collective responsibility. There is an emphasis on interactive modes of instruction and on learning through exploration, the teacher understands himself as a facilitator and guide in learning. Such concepts promote that learning shall energize learners and that learning tasks and goals shall be shared, challenging and multidisciplinary. Other important elements of participative learning are: positive interdependence, promotive face-to-face interaction, individual accountability and personal responsibility to achieve group goals, frequent use of the relevant interpersonal and small-group skills, and frequent and regular group processing of current functioning to improve the group's future effectiveness. In the past decades, participative learning has become a widely used instructional procedure in education.

Concepts and methods of participative learning include: collaborative /cooperative learning (Deutsch 1962, Johnson/Johnson 1999, Sego 1991), discovery-based learning, active and engaged learning (Jones et al. 1995), problem-based learning (Salvador et al. 1995), whole language approach (Lapp/Flood 1992), 
team learning (Senge 1990), Complex Instruction (Cl) (Cohen 1994), Constructive Controversy (Johnson/Johnson 1979), Cooperative Integrated Reading and Composition (Stevens et al. 1987), Cooperative Structures (Kagan 1985), Group Investigation (Sharan/Sharan 1976, 1992), Jigsaw (Aronson et al. 1978), Learning Together (Johnson/ Johnson 1999), Student Teams Achievement Divisions (Slavin 1978), Teams-Games-Tournaments (DeVries/Edwards 1974), Team Assisted Individualization (Slavin et al. 1982), Planning Games (Högsdal 1996), Action Learning Program (Donnenberg 1999).

Participatory learning and participatory culture mean that everyday life should be based on mutual learning and friendly, co-operative relationships. Others should be viewed as possible co-operators and as friends, not as enemies. In such a culture, knowledge, norms and values are constituted collectively and in bottom-up-processes, individuality unfolds within collectivity and collectivity within individuality. There is neither a plurality without unity nor a unity without plurality, but unity in plurality. Different life-styles and views exist and are integrated by general, universal, humanistic principles. Unity in plurality is a cultural outlook that fosters friendships and avoids wars and armed conflicts. It is an essentially peaceful worldview.

\section{Conclusion}

The above discussion shows that we are to a certain extent already witnessing a shift from a largely competitive mode of society to a more co-operative one. Numerous technological, ecological, economical, political, and cultural concepts, strategies, and material changes show this. However, at the same time we are witnessing new forms of economic centralisation that strengthen the dominance of economic autopoiesis over the other self-organizing realms of society. This development runs counter to the new cooperative principles put forward by new technologies and the increasingly networked character of society, and results in increased social risks. I doubt that the reaching of a noosphere can be achieved by strengthening the dominance of economic autopoiesis. New forms of globalisation and governance are needed. The world society is in need of global wisdom and global solidary forms of governance.

The world-system we live in is in a major crisis (Fuchs 2002f). This crisis has economical, political, ideological and ecological causes that cannot be reduced to a single cause (ibid.). Rather the complex interplay of diverse factors and antagonisms of the modern world system has led to a dynamic that endangers the survival of mankind and nature. Global problems such as poverty, the ecological crisis, war, pollution, the wasting of resources, unemployment, etc. have become a major threat to humanity. We are living in a phase of social chaos, instabilities and global crisis. More and more people in the world have to live under precarious conditions, even in the western-industrialised countries.

We are at a social and a historic crossroads today: The future development of society is not predetermined, but if the path of evolution does not change fundamentally, the end of mankind and the breakdown of our world system could take place in the decades to come. The global crisis is a major sign of the dangers we are facing today. But mankind has not been abandoned to some kind of pre-determined fate, because there are alternative evolutionary developments.

We cannot steer the evolution of social systems, but maybe we can give a certain direction to it during a phase of instability. We will not have certainty, but by gaining competence in co-operation, participation, and self-determination we can increase the chance that evolution will take certain directions (such as the survival of mankind) and that it won't take others (such as the escalation of the global problems and the ultimate destruction of mankind and society). During phases of instability and crises we find points where the further development of history is not determined, but relatively open. Such points again and again show up, but it is not determined how the outcome will look like. They are an expression of antagonistic forces that lead to social crises and instabilities. Is our behaviour determined by social structures? Or can we freely decide how to change these structures? Or can both views be integrated dialectically? Possibly, in phases of instability, social chaos and crisis, social actions are very important and influence the further development greatly. In such situations, small causes can have great effects. It is rather determined that a 
system like capitalism enters crisis and phases of instability periodically. But the outcome, the concrete course and point of time are left to chance.

The principle of co-operation can increase the possibility that we will not face ultimate destruction and that we will advance towards an inclusive, integrative society that is based on the principle of selforganization in all social areas and makes a socially and ecologically development of society possible. The key to the solution of the global problems is the self-determined self-organization of those groups and individuals that are facing more and more precarious social, economical, political, cultural and ecological conditions today.

Modern society is a historical system; this means that it has a beginning and an end. It is determined that this system will come to an end, but not when and how this will occur. I agree with Immanuel Wallerstein that the next 50 years will be a phase of instability; the global problems and the levels of national and international violence will increase

This is all due to the antagonistic social structures of capitalism. The outcome is not determined, rather relatively open. It depends upon the social struggles and resulting emancipatory social actions. We have no guarantees that a sustainable development will be the result, but the fact is that progress is possible, but certainly not inevitable. "The future [...] is open to possibility, and therefore to a better world" (Wallerstein 1997b). Immanuel Wallerstein also points out that this crisis can be seen as a crossroads of the historical development of society: "...this structural crisis leads us into a dark period of struggle over what kind of system will succeed the existing one. We can think of this as a bifurcation, and therefore the beginning of a chaotic period, within which no one can predict the outcome, which is inherently indeterminate. There will be a new structure, a new order, but it may be either better or worse than the existing one. It depends on what we all do in the period of acute struggle and how clearly we understand the forces at work" (Wallerstein 1999b; see also Wallerstein 1997a, 1997b, 1998, 1999a, 2000; Hopkins/Wallerstein 1996).

One of the major factors responsible for the crisis of the world system is the antagonism of co-operation and competition (which is just another expression for the antagonisms between self-determination and heteronomy as well as between inclusion and exclusion), which is characteristic of modern society. Competitive processes and the logic of commodities still dominate the social world; social structures today are predominantly exclusive ones. Sustainable design of nature, alliance technology, participatory economy, participatory democracy and participatory culture are aspects of co-operation that as an integrated unity or co-operative model of social self-organization can help us solve global problems such as the pollution of nature, the destructive effects of high risk technologies, poverty, exploitation, wars, violent conflicts, racism, terrorism, nationalism, fundamentalism, and terrorism.

A change of dominance is necessary in order to solve our global problems and to save humanity from self-destruction: The dominance of co-operation by competition, of inclusion by exclusion has to be reversed. If this can be done, a fair, just and attractive society may be established that manages to get rid of its global problems. Inclusive, democratic and co-operative ones should replace the current destructive and competitive types of re-creation in order to establish a participatory mode of social self-organization/recreation.

Co-operation means that actors communicatively make concerted use of existing structures in order to create new structures. Structures are medium and outcome of co-operation in communicative settings with positive "symbiotic" relationships. Such relationships are intelligent, i.e. they are based on collective intelligence (Lévy 1997) or wisdom which describes social situations, processes and states where there is a participatory constitution, design and usage of rules and resources and which are considered fair, just and fulfilling by the involved actors, within the framework of individual participation.

Actors have certain goals and there are different ways of reaching them. Combining certain ways might be symbiotic in such a way that the goals don't interfere and by co-operation all participating actors can benefit from each other and reach their goals. A social "symbiosis" is a communicative setting where all actors benefit and no-one loses and a positive, intelligent whole emerges by co-operation. By co-operation 
collective intelligence can be reached, hence one can also speak of co-operative intelligence (Fuchs/Stockinger 2002).

Social systems are problem-solving systems. In order to do so, they are auto- and re-creative, they create new reality and new environments. These systemic capabilities can be designed in different ways, co-operation is one of them. By communicating and co-operating, desirable social settings and mutual benefits can be reached. There are different forms of communication, action and designing society. There are also different ways of co-operating. Participatory co-operation can be intelligent co-operation so that all involved communication partners have advantages and can benefit. Intelligent co-operation is a way of creating new reality in re-creative loops. By intelligent co-operation structures can emerge that enable a participatory and sustainable design of society and social systems. If this is the case, one can speak of the emergence of Co-operative Intelligence. Co-Operative Intelligence and Intelligent Co-Operation can emerge in auto- and re-creative loops where social actions and communications are co-ordinated intelligently so that a new intelligent whole emerges that enables a participatory and sustainable design by acting and communicating.

\section{References}

Ackoff, R. L. (1981) Creating the Corporate Future. New York. Wiley.

Ahl, V.IAllen, T.F.H. (1996) Hierarchy Theory. New York. Columbia University Press.

Albers, O. (2001) Zukunftswerkstatt und Szenariotechnik. Schnell und innovative die Unternehmenszukunft gestalten.

Regensburg/Düsseldorf/Berlin. Fit for Business.

Argyris, C./Schön, D. (1999) Die lernende Organisation. Stuttgart. Klett-Cotta.

Aronson, E. et al. (1978) The jigsaw classroom. Beverly Hills, CA. Sage

Augros, Robert/Stanciu, George (1992) Competition and the Enculturation of Science. In: Combs (1992), pp. 126-135.

Axelrod, Robert (1984) The Evolution of Cooperation. New York, NY. Basic Books.

Banathy, Bela H. (1996) Designing Social Systems in a Changing World. New York/London. Plenum Press

Barber, Benjamin (1984) Strong Democracy: Participatory Politics for a New Age. Berkeley. University of California Press.

Beck, Ulrich (Ed.) (1999) Schöne neue Arbeitswelt. Vision: Bürgergesellschaft. Frankfurt am Main/New York. Campus.

Beer, S. (1994) Beyond Dispute. The Invention of Team Syntegrity. New York. Wiley.

Benedict, Ruth (1992) The Synergy Lectures. In: Combs (1992), pp. 58-67.

Beyerle, Matthias (1994) Staatstheorie und Autopoiesis: über die Auflösung der modernen Staatsidee im nachmodernen Denken durch die Theorie autopoietischer Systeme und der Entwurf eines nachmodernen Staatskonzepts. Frankfurt am Main etc. Lang

Bloch, Ernst (1986) The Principle of Hope. 3 Vol. Cambridge, Mass. MIT Press

Bookchin, Murray (1991) Libertarian Municipalism: An Overview. In: Green Perspectives, 24, October 1991.

Bourdieu, Pierre (1977) Outline of a Theory of Practice. Cambridge. Cambridge University Press.

Bourdieu, Pierre (1986) Distinction. A Social Critique of the Judgement of Taste. London. Routledge

Bourdieu, Pierre (1990a) In Other Words. Essays Towards a Reflexive Sociology. Cambridge/Oxford. Polity Press.

Bourdieu, Pierre (1990b) The Logic of Practice. Stanford. Stanford University Press.

Bruechler, Stephan/Simonis, Georg/Sundermann, Karsten (Eds.) (1999) Handbuch Technikfolgenabschätzung. 3 Volumes. Berlin. Edition Sigma.

Bullinger, H. J. (1998) Mit Wissensmanagement neue Potentiale erschliessen. In: Deutsches Industrial Engineering Jahrbuch 1998.

Capra, F. (1992) Veränderungen im Management - Management der Veränderung. In: Lutz, C. (ED.) (1992) Das systemischevolutionäre Management. Wien. Orac. pp. 112-121

Carroll, Scott P./Loye, Jenella E. (1992) Natural Selection, Competition and Cooperation: Human Biology and Human Freedom. In: Combs (1992), pp. 136-146.

Center for Democracy and Citizenship (1995) By the People: Citizenship Training in AmeriCorps. Minnesota Extension Services.

Cohen, E. (1994). Designing groupwork: Strategies for the heterogeneous classroom. New York. Teachers College Press.

Cohen, J./Arato, A. (1992) Civil Society and Political Theory. Cambridge. MIT Press.

Coleman, James S. (1990) Foundations of Social Theory. Cambridge. Belknap.

Collier, John (2003) Fundamental Properties of Self-Organization. In: Arshinov, Vladimir/Fuchs, Christian (Eds.) (2003) Causality, Emergence, and Self-Organisation. Moscow. Russian Academy of Sciences.

Collier, John (2004) Self-Organisation, Individuation and Identity. In: Revue Internationale de Philosophie (forthcoming). http://www.kli.ac.at/personal/collierpdf/SOIIF.PDF

Combs, Allan (Ed.) (1992) Cooperation. Beyond the Age of Competition. The World Futures General Evolution Studies, Vol. 4. Amsterdam. Gordon and Breach. 
Corning, Peter A. (1998) The Synergism Hypothesis. In: Journal of Social and Evolutionary Systems, 21(2), pp. 133-172.

Corning, Peter A. (2001). The Emergence of "Emergence": Now What? The Answer (In A Word) Is Synergy. Paper prepared for the symposium on "The Role of Synergy in the Evolution of Complexity", Annual Meeting of the Human Behavior and Evolution Society, London, June $14^{\text {th }}-17^{\text {th }}, 2001$. Emergence. 4 (2002), No. 3.

Davidow, W./Malone, M. (1993) Das virtuelle Unternehmen. Frankfurt/New York. Campus

Darwin, Charles (1859) On the Origin of Species by Means of Natural Selection. London. Murray.

Darwin, Charles (1874) The Descent of Man and Selection in Relation to Sex. London. Murray.

Deleuze, Gilles (1993) Postskriptum ueber die Kontrollgesellschaften [Postscript on the societies of control]. In: Deleuze, Gilles (1993) Unterhandlungen. 1972-1990. Frankfurt/Main. Suhrkamp.

Deppe, J. (1992) Quality Circle und Lernstatt. Wiesbaden. Gabler.

Deutsch, M. (1962) Cooperation and trust: Some theoretical notes. In: JONES (Ed.) Nebraska symposium on motivation . Lincoln, NE. University of Nebraska Press. pp. 275-319.

DeVries, D./Edwards, K. (1974) Student teams and learning games: Their effects on cross-race and cross-sex interaction. In: Journal of Educational Psychology, 66. pp. 741-749.

Donnenberg, O. (Ed.) (1999) Action Learning. Stuttgart. Klett-Cotta.

Eberly, D.E. (Ed.) (1994) Building a Community of Citizens: Civil Society in the 21st Century. Lanham, MD. University Press of America and the Commonwealth Foundation for Public Policy Alternatives.

Edmonds, Bruce (1999) What is Complexity? - The Philosophy of Complexity per se with Application to Some Examples in Evolution. In: Heylighen, F./Aerts, D. (Eds.) (1997) The Evolution of Complexity. Dordrecht. Kluwer.

Eisler, Riane/Combs, Allan (1992) Cooperation, Competition, and Gylany: Cultural Evolution from a New Dynamic Perspective. In: Combs (1992), pp. 75-85.

Engels, Friedrich (1886a) Dialektik der Natur. In: MEW, Vol. 20. Berlin. Dietz. pp. 305-570.

Espejo, R./Schwaninger, M. (Eds.) (1998) To Be and Not To Be, that is the System. A Tribute to Stafford Beer. Wiesbaden: Karl Auer Systeme Verlag

Etzioni, A. (1993) The Spirit of Community: The Reinvention of American Society. New York. Touchstone.

Etzioni, A. (Ed.) (1995) New Communitarian Thinking: Persons, Virtues, Institutions and Communities. Charlottesville. University of Virginia Press.

Etzioni, A. (2001) The Monochrome Society. Princeton. Princeton University Press.

Fenzl, Norbert/Hofkirchner, Wolfgang (1997) Information Processing in Evolutionary Systems. In: Schweitzer, F. (Ed.) SelfOrganization of Complex Structures: From Individual to Collective Dynamics, Gordon and Breach, London 1997, pp. 59-70

Fleissner, Peter/Hofkirchner, Wolfgang (1996) Emergent Information. In: BioSystems 2-3(38)/1996, pp. 243-248

Flood, R. L./Carson, E. R. (1993) Dealing with Complexity: An Introduction to the Theory and Application of Systems Science. New York. Plenum Press.

Flood, R.L./Jackson, M. (1991) Creative Problem Solving. New York. Wiley

Fotopoulos, Takis (1995) Towards an Integrative Democracy. London \& New York: Cassel.

Foucault, Michel (1976) Überwachen und Strafen. Frankfurt/Main. Suhrkamp.

Frenken, Koen (2000) A complexity approach to innovation networks. In: Research Policy, 29 (2000), pp. 257-272.

Fuchs, Christian (2001a) Leben und Selbstorganisation im postfordistischen, neoliberalen, informationsgesellschaftlichen Kapitalismus, Internet: http://cartoon.iguw.tuwien.ac.at/christian/gesellschaft.html.

Fuchs, Christian (2001b) Soziale Selbstorganisation im informationsgesellschaftlichen Kapitalismus, Libri BOD, Vienna/Norderstedt.

Fuchs, Christian (2002a) Dialectical Philosophy and Self-Organisation . INTAS Project "Human Strategies in Complexity"-Research Paper. In: Arshinov, Vladimir/Fuchs, Christian (Eds.) (2003) Causality, Emergence, Self-Organisation. Moscow. Russian Academy of Sciences (forthcoming).

Fuchs, C. (2002b) Concepts of Social Self-Organisation. INTAS-Project "Human Strategies in Complexity"-Research Report, 69 pages, Vienna University of Technology, Online at: http://www.self-organization.org

Fuchs, C. (2002c) The Role of the Individual in the Social Information Process. FIS (Foundations of Information Science) EConference 2002 Paper. In: FIS 2002 Proceedings. Entropy, 5 (1): 34-60. http://www.mdpi.org/entropy/papers/e5010034.pdf

Fuchs, C. (2002d) Structuration Theory and Self-Organization. INTAS-Project "Human Strategies in Complexity"-Research Paper. In: Systemic Practice and Action Research, 16 (2): 133-167.

Fuchs, C. (2002e) Some Implications of Pierre Bourdieu's Works for a Theory of Social Self-Organisation. INTAS-Project "Human Strategies in Complexity“-Research Paper. In: European Journal of Social Theory. 6(4) (forthcoming).

Fuchs, C. (2002f) Krise und Kritik in der Informationsgesellschaft. Arbeiten ueber Herbert Marcuse, kapitalistische Entwicklung und Selbstorganisation, Libri BOD, Vienna/Norderstedt.

Fuchs, C. (2002g) On the Topicality of Selected Aspects of Herbert Marcuse's Works. In: Fuchs (2002f). Online: http://cartoon.iguw.tuwien.ac.at/christian/marcuse/marcuseENG.html

Fuchs, C. (2002h) Software Engineering and the Production of Surplus Value. In: Cultural Logic. 4(3). http://www.eserver.org/clogic/2002/fuchs.html

Fuchs, C. (2002i) Some Implications of Anthony Giddens' Works for a Theory of Social Self-Organization. In: Emergence. 4(3): 7-35. 
Fuchs, Christian (2002j) Modern Society - A Complex, Evolutionary, Self-Organising, Antagonistic System. INTAS Project "Human Strategies in Complexity"-Research Paper. In: Social Science Research Network eLibrary: http://ssrn.com/abstract=385220 (published as The Self-Organisation of Modern Society. In: Studies in Political Economy, Vol. 25 (2003) (forthcoming).

Fuchs, Christian (2002k) Social Information and Self-Organization. In: Trappl, Robert (Ed.) (2002) Cybernetics and Systems 2002. Proceedings of the 16th European Meeting on Cybernetics and Systems Research. Vienna. Austrian Society for Cybernetic Studies. pp. 225-230.

Fuchs, Christian (2003a) The Self-Organisation of Politics, Power and the Nation State. In: Social Science Research Network eLibrary: http://ssrn.com/abstract=385222

Fuchs, Christian (2003b) Dialectical Materialism and the Self-Organization of Matter. In: Seeking Wisdom, Vol. 1 (No. 1). http://seekingwisdom.com/fuchs.htm

Fuchs, Christian/Hofkirchner, Wolfgang (2001) Theorien der Globalisierung, In: Zeitschrift Marxistische Erneuerung. 48 (Dec. 2001 ): 21-34. http://cartoon.iguw.tuwien.ac.at/christian/globalisierungz.html.

Fuchs, Christian/Hofkirchner, Wolfgang (2002a) Globalisierung: Ein allgemeiner, dialektischer Prozess der Menschheitsgeschichte. In: Zeitschrift Marxistische Erneuerung. 49 (March 2002): 89-102. http://cartoon.iguw.tuwien.ac.at/christian/globalisierungz2.html.

Fuchs, Christian/Hofkirchner, Wolfgang (2002b) Postfordistische Globalisierung. In: Zeitschrift Marxistische Erneuerung. 50 (June 2002): 152-165. http://cartoon.iguw.tuwien.ac.at/christian/globalisierungz3.html.

Fuchs, Christian/Hofkirchner, Wolfgang (2002c) Information in Social Systems. In: Schmitz, Walter (Ed.) Sign Processes in Complex Systems, Proceedings of the 7th International Congress of the IASS-AIS. Thelem. Dresden 2002, ISBN 3-933592-21-6.

Fuchs, Christian/Hofkirchner, Wolfgang (2003) Studienbuch Informatik und Gesellschaft, Libri BOD, Wien/Norderstedt.

Fuchs, Christian/Hofkirchner, Wolfgang/Klauninger, Bert (2001) The Dialectic of Bottom-Up and Top-Down Emergence in Social Systems. Talk at the Congress "Problems of Individual Emergence", Amsterdam, 16.-20.4.2001, in Proceedings of the Congress "Problems of Individual Emergence" (forthcoming). In: Social Science Research Network eLibrary: http://ssrn.com/abstract=385185

Fuchs, Christian/Schlemm, Annette (2002). "The Self-Organisation of Society," INTAS Project "Human Strategies in Complexity"-Research Paper. In: Natur \& Ökonomie. 1(1) (forthcoming). In: Social Science Research Network eLibrary: http://ssrn.com/abstract=385284

Fuchs, Christian/Stockinger, Gottfried (2002). The Autocreativity of Social Communication Systems and the Re-Creativity of Social Action Systems. In: Arshinov, Vladimir/Fuchs, Christian (Eds.) (2003) Causality, Emergence, Self-Organisation. Moscow. Russian Academy of Sciences (forthcoming).

Fuchs-Kittowski, Klaus (1997) Information neither Matter nor Mind On the Essence and on the Evolutionary Stage Concept of Information. in The Quest for a Unified Theory of Information (W. Hofkirchner, ed.). World Futures. 1997, 50: 551-570.

Gethmann, C./Grunwald, A. (1996) Technikfolgenabschätzung: Konzeptionen im Überblick. Bad Neunahr-Ahrweiler.

Giddens, Anthony (1981) A Contemporary Critique of Historical Materialism. Vol. 1: Power, Property and the State, Macmillian: London/Basingstoke.

Giddens, Anthony (1984) The Constitution of Society. Outline of the Theory of Structuration. Cambridge. Polity Press

Giddens, Anthony (1985) A Contemporary Critique of Historical Materialism. Vol. 2: The Nation-State and Violence, Polity Press: Cambridge.

Giddens, Anthony (1993) Sociology. Cambridge. Polity Press.

Gittell, R. (1998) Community Organizing. Thousand Oaks, CA. Sage.

Göbel, Elisabeth (1998) Theorie und Gestaltung der Selbstorganisation. Berlin. Duncker und Humblot

Goldstein, Jeffrey (1999) Emergence as a Construct: History and Issues. In: Emergence 1, 1, pp. 49-72.

Habermas, Jürgen (1984). The Theory of Communicative Action. Vol. 1., Beacon Press, Boston.

Haken, Hermann (1987) Die Selbstorganisation der Information in biologischen Systemen aus der Sicht der Synergetik. In: Küppers, Bernd-Olaf (Ed.) (1987) Ordnung aus dem Chaos- Prinzipien der Selbstorganisation und Evolution des Lebens. München. Piper. pp. 127-156

Hammer, Michael/Champy, James (1995) Business Reengineering. Frankfurt/New York. Campus

Haralambos, Michael/Holborn, Martin (1991) Sociology. Themes and Perspectives. London. CollinsEducational.

Hardt, Michael/Negri, Toni (1994) Labor of Dionysus. Minneapolis: Univ. of Minnesota Press.

Hardt, Michael/ Negri, Toni (2000) Empire. Cambridge, Mass./London: Harvard University Press.

Hayek, Friedrich August (1949) Individualism and Economic Order. London. Routledge \& Kegan.

Hayek, Friedrich August (1969) Grundsätze einer liberalen Gesellschaftsordnung. In: Hayek, F. A. (1969) Freiburger Studien. Tübingen. Mohr. pp. 108-125.

Hayek, Friedrich August (1988) The Fatal Conceit. The Errors of Socialism. Collected Works, Vol. 1. London. Routledge

Hegel, Georg Wilhelm Friedrich (1874) The Logic of Hegel. Translated from the Encyclopaedia of the Philosophical Sciences by William Wallace. 2nd Edition. London. Oxford University Press

Heylighen, Francis (1992) Evolution, Selfishness and Cooperation; Selfish Memes and the Evolution of Cooperation. In: Journal of Ideas, Vol. 2, No. 4, pp 70-84.

Heylighen, Francis (1996) What is Complexity? http://pespmc1.vub.ac.be/COMPLEXI.html 
Heylighen, Francis (1997) The Growth of Structural and Functional Complexity during Evolution. In: Heylighen, F./Aerts, D. (Eds.) (1997) The Evolution of Complexity. Dordrecht. Kluwer.

Hofkirchner, Wolfgang (1998a) Emergence and the Logic of Explanation. An Argument for the Unity of Science. In: Acta Polytechnica Scandinavica, Mathematics, Computing and Management in Engineering Series 91, 23-30

Hofkirchner, Wolfgang (1998b). Information und Selbstorganisation: Zwei Seiten einer Medaille. in: Fenzl, N., Hofkirchner, W., Stockinger, G. (Ed.) (1998) Information und Selbstorganisation: Annäherung an eine vereinheitlichte Theorie der Information. Studien-Verlag. Innsbruck/Wien. pp. 69-102.

Hofkirchner, Wolfgang (1999a) Towards a Unified Theory of Information - The Merging of Second-Order Cybernetics and Semiotics into a Single and Comprehensive Information Science. In: 15e Congrès International de Cybernétique, Namur 1998, Namur 1999, pp. 175-180.

Hofkirchner, Wolfgang (1999b) Ways of Thinking and the Unification of Science. In: Allen, J. K., Hall, M. L. W., Wilby, J. (Eds.), Proceedings of the 43rd Annual Conference of ISSS (The International Society for the Systems Sciences), ISBN 09664183-2-8 (CD-ROM), 1999

Hofkirchner, Wolfgang (2001) The Hidden Ontology: Real World Evolutionary Systems Concept as Key to Information Science. In: Emergence 3/3, 2001, pp. 22-41.

Hofkirchner, Wolfgang (2002a) Capabilities of (and Results of Processes in) Self-Organising and Information Generating/Sign Systems. INTAS Project "Human Strategies in Complexity"-Working Paper.

Hofkirchner, Wolfgang (2002b) Projekt Eine Welt: Kognition, Kommunikation, Kooperation. Versuch über die Selbstorganisation der Informationsgesellschaft. Münster. LIT.

Hofkirchner, Wolfgang/Fuchs, Christian (2003) The Architecture of the Information Society. In: Wilby, Jennifer/Allen, Janet K. (Eds.) (2003) Proceedings of the $47^{\text {th }}$ Annual Conference of the International Society for the Systems Sciences (ISSS): Agoras of the Global Village, Iraklion, Crete, July $7^{\text {th }}-11^{\text {th }}, 2003$. ISBN 0-9740735-1-2.

Högsdal, B. (1996) Planspiele. Manager-Seminare. Bonn. May.

Hörz, H., and Röseberg, U. (1981). Materialistische Dialektik in der physikalischen und biologischen Erkenntnis, Akademie, Berlin. Illich, Ivan (1975) Tools for Conviviality. London.

Jantsch, Erich (1975) Design for Evolution. New York. George Braziller.

Jenner, R.A. (1998) Dissipative Enterprises, Chaos, and the Principles of Lean Organizations. In: Omega. Int. J. Mgmt Sci., Vol. 26, No. 3, pp. 397-407.

Johnson, David W./Johnson, Roger T. (1979) Conflict in the classroom: Controversy and learning. Review of Educational Research, 49, pp. 51-70.

Johnson, David W./Johnson, Roger T. (1992) Preparing Children to Live in an Interdependent World. In: Combs (1992), pp. 193202.

Johnson, David W./Johnson, Roger T. (1999) Learning together and alone: Cooperative, competitive, and individualistic learning. Boston. Allyn \& Bacon.

Jungk, R./Müllert, N. (1989) Zukunftswerkstätten. Hamburg. Heyne.

Kagan, S. (1985) Cooperative learning resources for teachers. Riverside, CA. University of California at Riverside.

Kauffman, Stuart (1993) The Origins of Order. Oxford. Oxford University Press.

Khandwalla, Pradip N. (1977) The Design of Organizations. New York. Harcourt Brace Jovanovich.

Kropotkin, Peter (1913) Der Anarchismus. Ursprung, Ideal und Philosophie. Edited by Heinz Hug. Grafenau. Trotzdem. 1994.

Kropotkin, Peter (1914) Gegenseitige Hilfe in der Tier- und Menschenwelt. Vieanna/Grafenau. Monte Verita/Trotzdem. 1989.

Krugman, Paul (1996) The Self-Organizing Economy. Malden, Mass./Oxford. Blackwell

Lapp, D./Flood, J. (1992) Teaching reading to every child. New York. Macmilliam.

Laszlo, Ervin (1992) Cooperative Governance. In: Combs (1992), pp. 238-244.

Laszlo, E. (1996) Evolution: the general theory. Cresskill, New Jersey. Hampton.

Laszlo, E./Liechtenstein, A. v. (1992) Evolutionäres Management: Globale Handlungskonzepte. Fulda. Paidia

Leder, M. (1990) Innovationsmanagement. In: Albach, H. (Ed.) (1990) Innovationsmanagement. Wiesbaden.

Lévy, Pierre (1997) Collective Intelligence. Mankind's Emerging World in Cyberspace. New York. Plenum.

Ludwig, Bjørn (1995) Methoden zur Modellbildung in der Technikbewertung. CUTEC-Institut. Göttingen. Cuvillier

Luhmann, N. (1995) Social Systems, Stanford University Press: Stanford.

Lutz, Christian (Ed.) (1992) Das systemissch-evolutionäre Management. Wien. Orac

Lutz, R. (1994) Innovations-Ökologie. Strategien für ein umweltbewußtes Management. Frankfurt/Berlin.

Malik, F. (2000) Systemisches Management, Evolution, Selbstorganisation. Bern. Haupt.

Mansbridge, J. (1980) Beyond Adversary Democracy. New York. Basic Books.

Martinez, M.T. et al. (2001) Virtual Enterprise - Organisation, Evolution and Control. In: Int. J. of Production Economics, 74 (2001), pp. 225-238.

Marx, Karl (1867) Das Kapital. Berlin. Dietz. MEW, Vol. 23.

Massotte, P./Bataille, R. (2000) Future Production Systems: Influence of Self-Organization on Approaches to Quality Engineering.

In: Int. J. for Production Economics, 64 (2000), p. 359-377.

Mathews, C. (1994) Politics for People: Finding a Responsible Public Voice . Urbana/Chicago. University of Illinois Press. 
May, Christopher (2000) Knowledge Workers, Teleworkers and Plumbers: Labour in the Global Information Economy. In: Online-

Proceedings of the 41st Annual Convention of the International Studies Association. http://www.ciaonet.org/isa/mac01/.

Miller, W. J. (1996) A working definition for total quality management. In: Journal of Quality Management, v 1, pp. 149 - 159.

Nonaka, I./Takeuchi, H. (1995) The Knowledge-Creating Company. Oxford University Press.

Oberquelle, Horst (1991) Kooperative Arbeit und menschengerechte Groupware als Herausforderung für die Software-

Ergonomie. In: Oberquelle (Ed.) (1991) Kooperative Arbeit und Computerunterstützung. Stand und

Perspektiven. Göttingen/Stuttgart. Verlag für Angewandte Psychologie. pp. 1-10.

Pedler, M. et al. (1994) Das lernende Unternehmen. Frankfurt/New York. Campus.

Probst, G. (1983) Qualitäts-Management. Bern. Haupt.

Probst, G. (1987) Selbst-Organisation. Berlin. Parey.

Romme, A. G. L. (1995) Self-Organizing Processes in Top Management Teams. In: Journal of Business Research 34 (1995), pp. $11-34$.

Rubin, H./Rubin, I. (2001) Community Organizing and Development. Needham Heights, MA. Allyn \& Bacon .

Ryf, B. (1993) Die atomisierte Organisation. Wiesbaden. Gabler.

Sagan, Dorion/Margulis, Lynn (1992) Bacterial Bedfellows. In: Combs (1992), pp. 121-125.

Salthe, S. N. (1985) Evolving Hierarchical Systems. New York. Columbia University Press.

Salthe, S. N. (1993) Development and Evolution. Cambridge, MA. MIT Press.

Salvador, R.J. et al. (1995) Incorporating Problem-Based Teaching in the Agriculture Curriculum. In: J. Nat. Resour. Life Sci. Educ. 24(1), pp. 58-63.

Schmidt, Kjeld/Bannon, Liam (1992) Taking CSCW Seriously - Supporting Articulation Work. In: Computer Supported Cooperative Work (CSCW), Vol. 1 (1992), No. 1-2. pp. 7-40.

Schwaninger, M. (1989) Integrale Unternehmensplanung. Frankfurt/New York. Campus.

Schweitzer, Frank/Silverberg, Gerald (Eds.) (1998) Evolution und Selbstorganisation in der Ökonomie. Selbstorganisation: Jahrbuch für Komplexität in den Natur-, Sozial- und Geisteswissenschaften. Band 9. Berlin. Duncker und Humblot

Sego, A. (1991) Cooperative Learning: A Classroom Guide. Cleveland, Ohio. Info-Tec.

Senge, P. M. (1990) The Fifth Discipline. The Art and Practicde of the Learning Organization. New York. Currency Doubleday

Sharan, S./Sharan, Y. (1976). Small group teaching. Englewood Cliffs, NJ. Educational Technology Publications.

Sharan, S./Sharan, Y. (1992) Group investigation: Expanding cooperative learning. New York. Teacher's College Press.

Slavin, R. (1978). Student teams and achievement divisions. Journal of Research and Development in Education, 12. pp.39-49.

Slavin, R. et al. (1986) Using student team learning . Baltimore. Johns Hopkins University

Spencer, Herbert (1884) The Man Versus The State, with Six Essays on Government, Society, and Freedom.. Indianapolis. Liberty Fund. 1992

Stevens, R. et al. (1987) Cooperative integrated reading and composition: Two field experiments. Reading Research Quarterly, 22, pp. 433-454.

Tams, H. (1998) Communitarianism: A New Agenda for Politics and Citizenship. Basingstocke. Macmillan.

Teilhard de Chardin, Pierre (1961). Die Entstehung des Menschen, Beck, München.

Teilhard de Chardin, Pierre (1965). Building the Earth, Dimension Books, Denville, N. J.

Teilhard de Chardin, Pierre (1966). Die lebendige Macht der Evolution, Walte, Olten.

Van der Heijden, K. (1996) Scenarios. The Art of Strategic Conversation. Chicester/New York. Wiley.

Vernadskij, V. I. (1997). Der Mensch in der Biosphäre. Zur Naturgeschichte der Vernunft (ed. by Wolfgang Hofkirchner), Peter Lang Verlag, Vienna.

Wack, P. (1985a) Scenarios. Unchartered Waters Ahead. In: Harvard Business Review 63, No. 5, pp. 72-79.

Wack, P. (1985b) Scenarios: Shooting the Rapids. In: Harvard Business Review 63, No. 6, pp. 135-150.

Wallerstein, Immanuel (1997a) The End of Certainties in the Social Sciences. Talk at the Seminar "Conceptos en Ciencias y Humanidades. Mexico City, Oct. 16, 1998. http://fbc.binghamton.edu/iwendcrt.htm

Wallerstein, Immanuel (1997b) Uncertainty and Creativity. Talk at Forum 2000: Concerns and Hopes on the Threshold of the New Millennium. Prague, Sept. 3-6, 1997. http://fbc.binghamton.edu/iwuncer.htm

Wallerstein, Immanuel (1998) Utopistics: or, Historical Choices for the Twenty-First Century. New York. New Press

Wallerstein, Immanel (1999a) Globalization or the Age of Transition? A Long-Term View of the World-System.

http://fbc. binghamton.edu/iwtrajws.htm

Wallerstein, Immanuel (1999b) Uncertainty and Historical Progress. http://fbc.binghamton.edu/iwposb.htm

Wallerstein, Immanuel (2000) Auf abschüssiger Strecke mit defekten Bremsen. In: Le Monde Diplomatique (German Edition).

11/08/2000. http://monde-diplomatique.de/mtpl/2000/08/11/a0037.stext?Name=askp6VVBa\&idx=1

Walze, Michael(1992) The Civil Society Argument. In: Mouffe, C. (Ed.) (1992) Dimensions of Radical Democracy: Pluralism,

Citizenship, Community. London: Verso. pp. 89-107.

Warnecke, H.-J. (1992) Die Fraktale Fabrik: Revolution der Unternehmenskultur. Berlin. Springer.

Warnecke, H.-J./Hüser, M. (1995) Lean production.In: International Journal of Production Economics 41 (1995), pp. 37-43. 
Weise, Peter (1998) Der Preismechanismus als ökonomischer Selbstorganisationsprozess. In: Schweitzer/Silverberg (1998). S. 315-331

Wildemann, H. (1992) Die modulare Fabrik. Zürich. Verlag Industrielle Organisation.

Wilkinson, lan/Young, Louise (2001) On cooperating Firms, relations and networks. In: Journal of Business Research, 55 (2002), pp. 123-132.

Willke, H. (1995) Das intelligente Unternehmen. Wissensmanagement der Organisation. In: Beratergruppe Neuwaldegg (Ed.) (1995) Intelligente Unternehmen. Wien. pp. 13-45.

Witt, Ulrich (1997) Self-organization and economics - what is new? In: Structural Change and Economic Dynamics 8 (1997). S. 489-507

Womack, J. et al. (1991) Die zweite Revolution in der Autoindustrie. Frankfurt/New York. Campus

World Commission on Environment and Development (1987) Unsere gemeinsame Zukunft. Der Brundtland-Bericht. Hrsg. von Volker Hauff. Greven. Eggenkamp 